\title{
Cortical Control of Subthalamic Neuronal Activity through the Hyperdirect and Indirect Pathways in Monkeys
}

\author{
${ }^{\circledR}$ Zlata Polyakova, ${ }^{1,2}{ }^{\circledR}$ Satomi Chiken, ${ }^{1,2,3}{ }^{\circledR}$ Nobuhiko Hatanaka, ${ }^{1,2,3}$ and ${ }^{\circledR}$ Atsushi Nambu ${ }^{1,2,3}$ \\ ${ }^{1}$ Division of System Neurophysiology, National Institute for Physiological Sciences, Okazaki 444-8585, Japan, ${ }^{2}$ Department of Physiological Sciences, \\ SOKENDAI (The Graduate University for Advanced Studies), Okazaki 444-8585, Japan, and ${ }^{3}$ Tokyo Metropolitan Institute for Neuroscience, Fuchu \\ 183-0042, Japan
}

The subthalamic nucleus (STN) plays a key role in the control of voluntary movements and basal ganglia disorders, such as Parkinson's disease and hemiballismus. The STN receives glutamatergic inputs directly from the cerebral cortex via the cortico-STN hyperdirect pathway and GABAergic inputs from the external segment of the globus pallidus (GPe) via the corticostriato-GPe-STN indirect pathway. The STN then drives the internal segment of the globus pallidus, which is the output nucleus of the basal ganglia. Thus, clarifying how STN neuronal activity is controlled by the two inputs is crucial. Cortical stimulation evokes early excitation and late excitation in STN neurons, intervened by a short gap. Here, to examine the origin of each component of this biphasic response, we recorded neuronal activity in the STN, combined with electrical stimulation of the motor cortices and local drug application in two male monkeys (Macaca fuscata) in the awake state. Local application of glutamate receptor antagonists, a mixture of an AMPA/kainate receptor antagonist and an NMDA receptor antagonist, into the vicinity of recorded STN neurons specifically diminished early excitation. Blockade of the striatum (putamen) or GPe with local injection of a $\mathrm{GABA}_{\mathrm{A}}$ receptor agonist, muscimol, diminished late excitation in the STN. Blockade of striatoGPe transmission with local injection of a $\mathrm{GABA}_{\mathrm{A}}$ receptor antagonist, gabazine, into the GPe also abolished late excitation. These results indicate that cortically evoked early and late excitation in the STN is mediated by the cortico-STN glutamatergic hyperdirect and the cortico-striato-GPe-STN indirect pathways, respectively.

Key words: basal ganglia; GABA; glutamate; hyperdirect pathway; indirect pathway; subthalamic nucleus

Significance Statement

Here we show that the subthalamic nucleus (STN), an input station of the basal ganglia, receives cortical inputs through the cortico-STN hyperdirect and cortico-striato-external pallido-STN indirect pathways. This knowledge is important for understanding not only the normal functions of the STN, but also the pathophysiology of STN-related disorders and therapy targeting the STN. Lesions or application of high-frequency stimulation in the STN ameliorates parkinsonian symptoms. These procedures could affect all components in the STN, such as afferent inputs through the hyperdirect and indirect pathways, and STN neuronal activity. If we can understand which component is most affected by such procedures, we may be able to identify more effective manipulation targets or methods to treat Parkinson's disease.

Received Apr. 3, 2020; revised Aug. 7, 2020; accepted Aug. 17, 2020.

Author contributions: A.N. designed research; Z.P., S.C., N.H., and A.N. performed research; Z.P., S.C., N.H., and A.N. analyzed data; Z.P., S.C., N.H., and A.N. wrote the paper.

The authors declare no competing financial interests.

This work was supported by Ministry of Education, Culture, Sports, Science and Technology (MEXT) KAKENHI ("Non-linear Neuro-oscillology," Grant 15H05873 to A.N.), Japan Society for the Promotion of Science KAKENHI (Grant 16 K07014 to S.C.; Grants 26250009 and 19KK0193 to A.N.), Japan Science and Technology Agency Core Research for Evolutional Science and Technology (Grant JPMJCR1853 to S.C.), Japan Agency for Medical Research and Development (Grant JP19dm0307005 to A.N.), and MEXT Scholarship (to Z.P.). We thank S. Sato, H. Isogai, N. Suzuki, K. Awamura, K. Miyamoto, and Y. Sugiyama for technical support; and Y. Yamagata for her critical reading of the manuscript.

Correspondence should be addressed to Atsushi Nambu at nambu@nips.ac.jp or Nobuhiko Hatanaka at hatanaka@nips.ac.jp.

https://doi.org/10.1523/JNEUROSC1.0772-20.2020

Copyright $\odot 2020$ the authors

\section{Introduction}

The subthalamic nucleus (STN) is an input station as well as a relay nucleus of the basal ganglia (BG) and plays a critical role in the control of voluntary movements. STN neurons change their activity in relation to limb and eye movements (Georgopoulos et al., 1983; DeLong et al., 1985; Matsumura et al., 1992; Wichmann et al., 1994). Recent studies demonstrated that STN activity is specific to inhibition or cancelation of movements or a change in task (Isoda and Hikosaka, 2008; Schmidt et al., 2013; Pasquereau and Turner, 2017; Schmidt and Berke, 2017). Lesions or chemical blockade of the STN reduces firing rates of neurons in the external segment of the globus pallidus (GPe) and the internal segment of the globus pallidus (GPi) and interferes with normal voluntary movements by inducing hemiballismus, a form of involuntary 
movement (Whittier and Mettler, 1949; Carpenter et al., 1950; Hamada and DeLong, 1992; Nambu et al., 2000). Abnormal activity of STN neurons, such as firing rate and pattern changes, has been reported in various movement disorders, such as Parkinson's disease (PD; Bergman et al., 1994; Hassani et al., 1996; RodriguezOroz et al., 2001; Galvan and Wichmann, 2008; Hanson et al., 2012) and dyskinesia (Levy et al., 2001; Alonso-Frech et al., 2006; Aristieta et al., 2012). Moreover, lesions or chronic high-frequency stimulation of the STN ameliorates PD symptoms (Bergman et al., 1990; Aziz et al., 1991; Benabid et al., 1994; Limousin et al., 1995; Alvarez et al., 2005; Martínez-Fernández et al., 2018). Therefore, understanding how steady-state and phasic STN activity is controlled by afferent inputs to the STN is important.

The STN receives somatotopically organized glutamatergic inputs directly from the frontal cortex, as an input station of the BG, forming the cortico-STN hyperdirect pathway (Monakow et al., 1978; Nambu et al., 1996, 2000, 2002b). The STN also receives GABAergic inputs from the GPe and acts as a relay nucleus in the striato-GPe-STN indirect pathway (Alexander and Crutcher, 1990). The STN projects to the GPe, GPi, and substantia nigra pars reticulata $(\mathrm{SNr})$, the $\mathrm{GPi}$ and $\mathrm{SNr}$ being the output stations of the BG, and controls their neuronal activity (Jaeger and Kita, 2011).

The STN is composed of glutamatergic neurons that fire spontaneously at mid-frequency $(20-40 \mathrm{~Hz})$. Cortical stimulation induces a biphasic response composed of early excitation and late excitation, interposed by a short "gap" (Nambu et al., 2000; Iwamuro et al., 2017). The origin of the biphasic response can be interpreted as follows: (1) early excitation and late excitation are mediated by the hyperdirect and indirect pathways, respectively, as shown in experiments with anesthetized rats (Ryan and Clark, 1991, 1992; Maurice et al., 1998); alternatively, (2) inhibition from the GPe through cortico-STN-GPe-STN transmission intervenes in cortically evoked long excitation in the STN, and rebound excitation after the inhibition may contribute to late excitation (Fujimoto and Kita, 1993). Currently, the exact origin of the biphasic response is not clear in nonhuman primates. The first goal of the present study is to investigate the origin of each component of the cortically evoked biphasic response in the STN using awake monkeys. The second goal is to examine the control mechanism of STN spontaneous activity through excitatory and inhibitory inputs mediated by the hyperdirect and indirect pathways, respectively.

\section{Materials and Methods}

Animals. The experimental protocols were approved by the local Institutional Animal Care and Use Committee, and all experiments were performed in accordance with the guidelines of the National Institutes of Health Guide for the Care and Use of Laboratory Animals. Two male Japanese monkeys (Macaca fuscata; Monkeys K8 and K9), weighing 5.8 and $5.5 \mathrm{~kg}$, were used in this study. Each animal was housed in an individual primate cage and had ad libitum access to food and water. Each monkey was trained to sit in a primate chair quietly.

Surgery. After the chair training, each monkey underwent an aseptic surgical operation to fix its head painlessly in a stereotaxic frame attached to a monkey chair (for details, see Nambu et al., 2000, 2002a). Briefly, under general anesthesia with sodium thiopental $(25 \mathrm{mg} / \mathrm{kg}$ body weight, i.v.), ketamine hydrochloride (10 mg/kg, i.m.), and xylazine hydrochloride ( $1-2 \mathrm{mg} / \mathrm{kg}$, i.m.), the head of the monkey was fixed in a stereotaxic apparatus, the skull was widely exposed and covered with transparent acrylic resin (Unifast II, GC Corporation), and two stainless steel pipes were mounted for head fixation. After drilling the skull, a stainless steel screw $(3.0 \mathrm{~mm}$ in diameter) was placed over the frontal cortex as an indifferent electrode. Antibiotics (amikacin sulfate) and analgesics (ketoprofen) were administered postsurgically.

After full recovery from the first operation, the second operation was performed. A portion of the skull over the primary motor cortex (M1) and supplementary motor area (SMA) was removed under anesthesia with ketamine hydrochloride $(10 \mathrm{mg} / \mathrm{kg}$, i.m.) and xylazine hydrochloride ( $1-2 \mathrm{mg} / \mathrm{kg}$, i.m.). Then, the forelimb regions of the M1 and SMA were identified by recording neuronal activity in response to somatosensory stimuli and by observing body part movements evoked by intracortical microstimulation (Fig. 1A). Based on the mapping, one pair of bipolar stimulating electrodes (enamel-coated stainless steel wires, 200 $\mu \mathrm{m}$ in diameter, with $2 \mathrm{~mm}$ intertip distance) was implanted chronically into the forelimb region of the SMA (Fig. 1A2), and two pairs were implanted into the distal forelimb (M1d) and proximal forelimb (M1p) regions of the M1 (Fig. 1A3). Exposed areas were covered with transparent acrylic resin except for two areas (10-15 $\mathrm{mm}$ in diameter) to access the putamen (Put), GPe, and STN. Two rectangular plastic chambers covering each craniotomy were fixed onto the skull with acrylic resin. Antibiotics, steroids (dexamethasone), and analgesics were administered after the surgical procedures. Recordings of neuronal activity were started after full recovery from the second surgery.

Recording STN neuronal activity. Recording of STN neuronal activity was performed 2 or $3 \mathrm{~d}$ /week for several months. During the experimental session, the monkey was seated in a primate chair with its head fixed in the frame, leaving its body and limbs free to move. Recordings were performed while the monkey was awake. First, the location and borders of the STN were defined based on single-unit extracellular recordings. Using a hydraulic microdrive (MO-81-S, Narishige), a glass-coated Elgiloy microelectrode $(0.7-1.5 \mathrm{M} \Omega$ at $1 \mathrm{kHz})$ was inserted vertically into the STN through the dura mater during local application of lidocaine. Neuronal activity in the STN recorded through the microelectrode was amplified (10,000-fold) and filtered $(0.3-2 \mathrm{kHz})$. Unitary activity of STN neurons was isolated, converted into digital data with a homemade time-amplitude window discriminator, and stored in a computer using LabVIEW software (National Instruments) for online and offline data analyses. Unitary activity and converted digital data were also stored on videotapes using a PCM recorder (Cygnus Technology). During recordings, the arousal level of the monkey was maintained by monitoring spontaneous firing rates and patterns of STN neuronal activity. Peristimulus time histograms (PSTHs; 1 ms bins, summed for 100-stimulus trials) were constructed to examine the responses to electrical stimulation through electrodes implanted in the M1 and SMA (bipolar stimulation, $300 \mu \mathrm{s}$ in duration, single pulse, $0.5-0.7 \mathrm{~mA}$ strength, $1.4 \mathrm{~s}$ intervals).

STN neurons could be identified by mid-frequency firings (20$40 \mathrm{~Hz}$ ), the responses to passive joint movements, and the pattern of the responses to cortical stimulation, and could be easily discriminated from surrounding structures, such as the zona incerta and lateral hypothalamus. The typical response pattern of STN neurons to cortical stimulation is early excitation and late excitation with a short intervening gap (Nambu et al., 2000; Iwamuro et al., 2017). In the present study, STN neurons with the biphasic response were studied because they were major (59\%; Iwamuro et al., 2017), and the main objective of the present study is to examine the origins of the biphasic response.

Drug injection in the vicinity of recorded STN neurons. Single-unit recordings of STN neurons in combination with local application of drugs were performed using an electrode assembly consisting of a glass-coated Elgiloy microelectrode $(0.7-1.5 \mathrm{M} \Omega$ at $1 \mathrm{kHz})$ and two silica tubes (outside diameter, $150 \mu \mathrm{m}$; inside diameter, $75 \mu \mathrm{m}$; Polymicro Technologies; Fig. $1 B$, inset in the large circle; Kita et al., 2004; Tachibana et al., 2008). The silica tubes were connected to two $25 \mu \mathrm{l}$ Hamilton microsyringes. Each syringe contained one of the following drugs dissolved in saline: (1) an AMPA/kainate receptor antagonist, 2,3-dihydroxy-6-nitro-7-sulfonylbenzo[f]quinoxaline (NBQX; 1 mM; Sigma-Aldrich); (2) an NMDA receptor antagonist, \pm 3 -(2-carboxypiperazin-4-yl)propyl-1-phosphonic acid (CPP; $1 \mathrm{~mm}$; Sigma-Aldrich); (3) a mixture of NBQX (0.5-1 mM) and CPP (0.5-1 mM); and (4) a $\mathrm{GABA}_{\mathrm{A}}$ receptor antagonist, gabazine (SR95531; 1 mm; Sigma-Aldrich). Using a hydraulic microdrive, the electrode assembly was inserted vertically into the STN through a small 


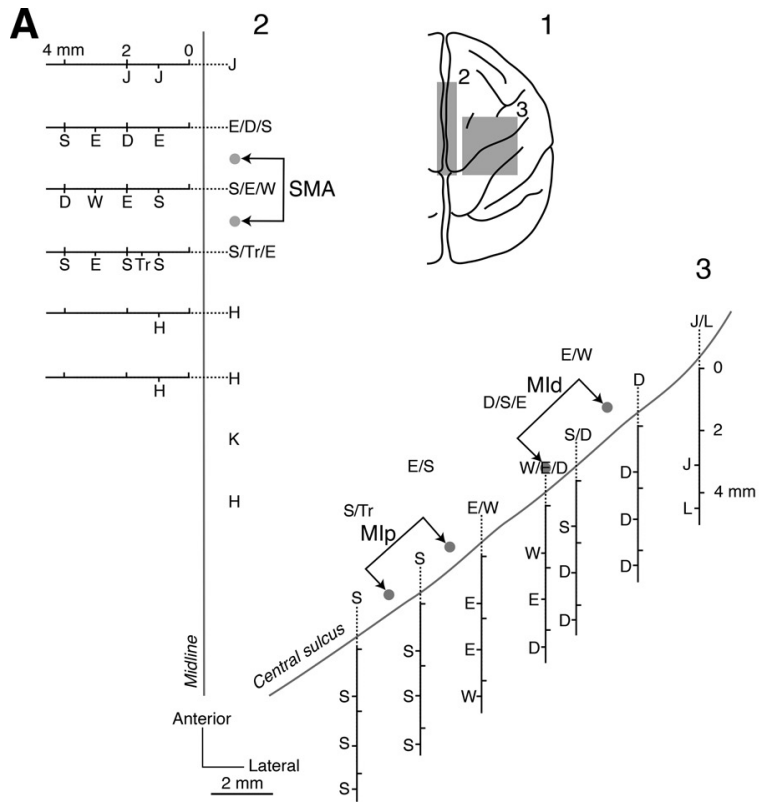

B

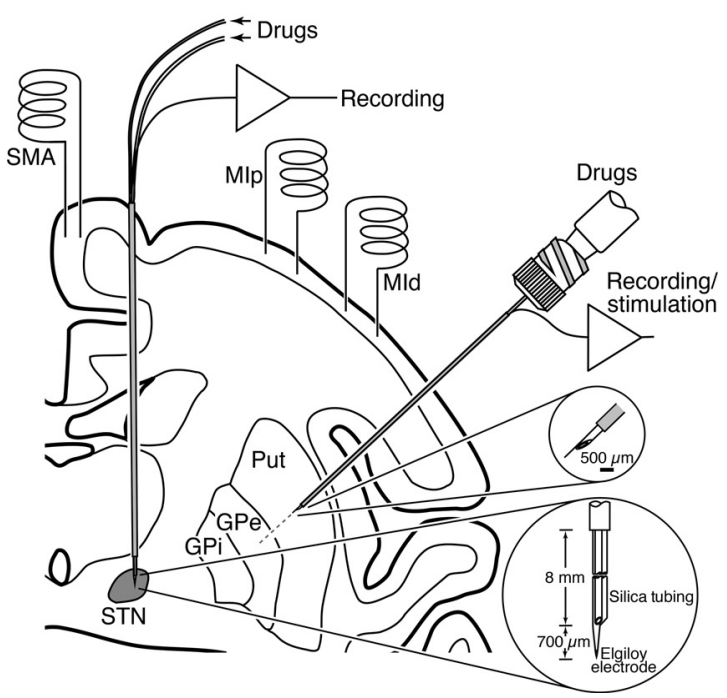

Figure 1. Cortical mapping and schematic representation of the experimental setup. $\boldsymbol{A}$, Cortical mapping of Monkey $\mathrm{K} 9$ for the implantation of stimulating electrodes. $\mathbf{A 1}$, Top view of the monkey brain. Gray regions indicate mapped areas shown in $\mathbf{A} \mathbf{2}$ and $\mathbf{A 3} . \mathbf{A 2}, \mathbf{A 3}$, Mapping of the SMA and M1, respectively. Somatotopic arrangements in the mesial surface and the anterior bank of the central sulcus are also shown along with the depth from the cortical surface. Each letter indicates a body part: D, digit; E, elbow; H, hip; K, knee; L, lip; J, jaw; $S$, shoulder; Tr, trunk; W, wrist. Three pairs of bipolar-stimulating electrodes were implanted into the loci indicated by small gray circles: the forearm region of the SMA and the proximal forelimb (M1p) and distal forelimb (M1d) regions of the M1. B, Schematic representation of the experimental setup. Bipolar stimulating electrodes were chronically implanted in the forelimb regions of the SMA, M1p, and M1d. The recording Elgiloy electrode with two silica tubes for microinjection (inset in the large circle) was introduced into the STN. The needle of a Hamilton microsyringe for drug injection (inset in the small circle) was inserted into the Put or GPe in some experiments.

incision in the dura mater during local application of lidocaine (Fig. 1B). STN neuronal activity was recorded, and PSTHs were constructed to examine the responses to cortical stimulation as described above. When STN neurons responded with early excitation and late excitation to M1 and/or SMA stimulation, a total volume of $0.2-0.6 \mu \mathrm{l}$ of each drug was injected at a rate of $0.03-0.05 \mu \mathrm{l} / \mathrm{min}$ (Table 1 ) by advancing plungers controlled by a computer (XF-320-J, Nihon Kohden). During drug injection, the waveform of STN activity was carefully monitored. The effective radius of this volume of drugs was estimated to be $\sim 1 \mathrm{~mm}$ (Kita et al.,
Table 1. Number of STN neurons tested with drug injections

\begin{tabular}{lccc}
\hline & Monkey K8 & Monkey K9 & Total \\
\hline Drug injection into STN $(n=33)$ & & & \\
NBQX + CPP & 6 & 4 & 10 \\
NBQX & 1 & 5 & 2 \\
NBQX, then CPP & 1 & & 6 \\
CPP, then NBQX & 1 & 4 & 1 \\
NBQX + CPP, then gabazine & 2 & 3 & 5 \\
Gabazine & 4 & & 5 \\
$\quad$ Gabazine, then NBQX + CPP & & & 4 \\
Drug injection into Put $(n=15)$ & 9 & 3 & 12 \\
$\quad$ Muscimol & & 3 & 3 \\
NBQX & 3 & 5 & 8 \\
Drug injection into GPe $(n=22)$ & 5 & 4 & 9 \\
$\quad$ Muscimol & 2 & 3 & 5 \\
Gabazine & 34 & 36 & 70 \\
$\quad$ NBQX & & & \\
Total &
\end{tabular}

Number of neurons in the STN tested with drug injections, including NBQX (AMPA/kainate receptor antagonist), CPP (NMDA receptor antagonist), gabazine (GABA receptor antagonist), or muscimol $\left(G_{A B A}\right.$ receptor agonist) into the vicinity of recorded STN neurons, Put, or GPe in two monkeys (K8 and K9).

2004), and thus, injection sites were located at least $1 \mathrm{~mm}$ apart. Then, PSTHs were constructed to examine changes in cortically evoked responses after drug injection. Drug effects became maximum 10-15 min after the injection, lasted for $30-40 \mathrm{~min}$, and decayed very slowly. Digitized spontaneous activity was also recorded for $50 \mathrm{~s}$ before and after drug injections, and autocorrelograms were constructed $(0.5 \mathrm{~ms}$ in bin width). Soon after the effect of the first drug was stabilized, the second drug was injected (Table 1). Thus, the effect after the second drug injection was considered as the effect of both the first and second drugs. We also confirmed that injections of saline alone did not alter spontaneous firing rates and patterns or cortically evoked responses of STN neurons.

Drug injection into the Put or GPe. First, the forelimb regions of the Put and GPe were mapped by recording neuronal activity. Using a hydraulic microdrive, a glass-coated Elgiloy microelectrode $(0.7-1.0 \mathrm{M} \Omega$ at $1 \mathrm{kHz}$ ) was inserted obliquely ( $45^{\circ}$ from vertical in the frontal plane) into the Put or GPe through the dura mater during local application of lidocaine. The forelimb regions of the Put and GPe were identified by firing patterns, somatosensory inputs, and the responses to cortical stimulation (Nambu et al., 2000, 2002a; Kita et al., 2004). The typical response pattern in the Put was monophasic excitation, and that in the GPe was a triphasic response composed of early excitation, inhibition, and late excitation.

The method for drug injection into the Put or GPe was the same as described previously (Fig. $1 B$; Nambu et al., 2000; Tachibana et al., 2008). A Teflon-coated tungsten wire (bare diameter, $50 \mu \mathrm{m}$ ) was attached to a 31 gauge needle (outside diameter, $270 \mu \mathrm{m}$ ) of a $10 \mu \mathrm{l}$ Hamilton microsyringe, and they were covered with polyamide tubing except for the tip ( $1 \mathrm{~mm}$; Fig. $1 B$, inset in the small circle). The tungsten wire was used not only as a recording electrode, but also as a bipolar stimulating electrode together with the syringe needle (intertip distance, $0.7 \mathrm{~mm}$ ). The Hamilton microsyringe contained one of the following drugs dissolved in saline: (1) a $\mathrm{GABA}_{\mathrm{A}}$ receptor agonist, muscimol (4.4$8.8 \mathrm{~mm}$; Sigma-Aldrich); (2) gabazine (10 mM); or (3) NBQX (10 mM). Using the same hydraulic microdrive for the mapping of the Put and GPe, the needle was inserted obliquely through a small incision in the dura mater during local application of lidocaine (Fig. $1 B$ ), and the orifice of the microsyringe was set at the center in the forelimb region of the Put or GPe by recording neuronal activity through the tungsten wire. For STN recording, a glass-coated Elgiloy microelectrode (0.7-1.5 $\mathrm{M} \Omega$ at $1 \mathrm{kHz}$ ) was inserted vertically using the second hydraulic microdrive, and neuronal activity was isolated. When an STN neuron responded with early excitation and late excitation to M1 and/or SMA stimulation, the neuronal response to the Put or GPe stimulation (bipolar stimulation, $300 \mu$ s in duration, single pulse, strength of $0.1-0.7 \mathrm{~mA}$, sometimes up to $1.0 \mathrm{~mA}, 1.4 \mathrm{~s}$ intervals) was examined, and then, a total volume of $1.0-4.0 \mu \mathrm{l}$ of a drug was injected in the following combinations 
(Table 1): (1) muscimol injection into the Put to block Put activity; (2) muscimol injection into the GPe to block GPe activity; (3) gabazine injection into the GPe to block Put-GPe GABAergic neurotransmission; and (4) NBQX injection into the GPe to block early excitation mediated by the cortico-STN-GPe pathway. The drug volume of 1.0-4.0 $\mu \mathrm{l}$ was necessary to cover the cortically responding region in the Put or GPe. During drug injection, the waveform of STN activity was carefully monitored. NBQX was also injected into the Put, but they were not analyzed because of a limited number of cases $(n=3$; Table 1$)$.

Data analysis. Neuronal responses to cortical stimulation and spontaneous firing rates and patterns were analyzed using Igor Pro software (version 6.3, WaveMetrics) and compared before and after drug injections into the STN, Put, or GPe. When STN neurons responded to multiple cortical sites, the biphasic response with the larger amplitude was used for analyses. The numbers of STN neurons examined with different combinations and orders are listed in Table 1. Responses of STN neurons evoked by stimulation of the M1, SMA, Put, and GPe were evaluated based on PSTHs. The mean and SD of discharge rates during the $100 \mathrm{~ms}$ period preceding the onset of stimulation were calculated for each PSTH, and considered to be the baseline discharge rate. Excitatory responses to stimulation were judged to be significant if firing rates during at least two consecutive bins $(2 \mathrm{~ms})$ reached the statistical level of the mean +3.09 SD (corresponding to $p=0.001$, one-tailed $t$ test; Fig. 2, dotted gray lines). The latency of significant responses was defined as the time when firing rates first exceeded the statistical level of the mean +1.65 SD (corresponding to $p=0.05$, onetailed $t$ test; Fig. 2, dashed gray lines; Iwamuro et al., 2017). The duration of significant responses was defined as the period over this level (greater than or equal to the mean $+1.65 \mathrm{SD}$ ). The amplitude was calculated as the number of spikes during significant responses minus that of the baseline discharge (the area of significant responses above the mean; Fig. 2 , orange areas with ${ }^{*}$ and $\left.{ }^{*}\right)$. Inhibitory responses were judged to be significant if firing rates during at least two consecutive bins $(2 \mathrm{~ms})$ were below the mean $-1.65 \mathrm{SD}$ or were equal to 0 . The latency was defined as the time when the firing rate first dropped below this level (less than or equal to the mean $-1.65 \mathrm{SD}$, or equal to 0 ), the duration was defined as the period below this level, and the amplitude was calculated as the number of spikes of the baseline discharge minus that during significant responses (the area of significant responses below the mean; Fig. 2, light blue areas with $\boldsymbol{\nabla}$ ). The gap between cortically evoked early and late excitation was judged to be significant if firing rates during at least two consecutive bins $(2 \mathrm{~ms}$ ) were below the mean $+1.65 \mathrm{SD}$. The latency was defined as the time when the firing rate first dropped below this level (less than or equal to the mean $+1.65 \mathrm{SD}$ ), the duration was defined as the period below this level, and the amplitude was calculated as the mean +1.65 SD minus the number of spikes during the gap (area of the gap below the mean +1.65 SD; Fig. 2, light blue areas with $\boldsymbol{\nabla}$ ). The amplitude and duration of cortically evoked responses in the STN were analyzed before and after drug injections into the STN, Put, or GPe. Population PSTHs of STN neurons were constructed by averaging PSTHs of all responsive neurons and smoothing with a Gaussian filter $(\sigma=1.6 \mathrm{~ms})$ for each case of drug injections, and were displayed with $\pm \mathrm{SD}$.

Spontaneous firing rates and patterns were analyzed using continuous digitized recordings for $50 \mathrm{~s}$. The following parameters were calculated: mean and SD of firing rates; burst index (BI), defined as the ratio of the mean and the mode of interspike intervals (ISIs); and coefficient of variation (CV) of ISIs defined as the ratio of the SD and the mean of ISIs. Spontaneous firing patterns were also analyzed by calculating autocorrelograms ( $0.5 \mathrm{~ms}$ bin width, for $50 \mathrm{~s})$. The mean and SD of coefficient values between 900 and $1000 \mathrm{~ms}$ (200 bins), which was far enough from time 0 , were calculated as control values because of the flat nature of autocorrelograms during this period. Peaks and troughs of autocorrelograms were judged to be significant if values during at least two consecutive bins ( $1 \mathrm{~ms})$ exceeded the mean $\pm 2.58 \mathrm{SD}$ ( $p=0.005$, one-tailed $t$ test; Tachibana et al., 2008). The regularity of firings was assessed by the number of peaks and their heights in the autocorrelograms. Adequate and stable spike isolation during a recording session was confirmed by constructing ISI histograms: absence of ISIs $<2 \mathrm{~ms}$ (the refractory period).

Experimental design and statistical analysis. One-tailed paired $t$ tests were used to compare parameters before and after drug injections ( $p<0.05$ or $p<0.01$ was considered significant). One-tailed unpaired $t$ tests were used to compare parameters between M1 and SMA stimulation ( $p<0.01$ or $p<0.001$ was considered significant).

Histology. At the end of the experiments, the recording and drug injection sites were marked by current injections (cathodal DC of $20 \mu \mathrm{A}$ for $30 \mathrm{~s}$ ). Monkeys were deeply anesthetized with sodium thiopental $(50 \mathrm{mg} / \mathrm{kg}$, i.v.), ketamine hydrochloride $(10 \mathrm{mg} / \mathrm{kg}$, i.m.), and xylazine hydrochloride (1-2 mg/kg, i.m.), and perfused transcardially with $0.1 \mathrm{M}$ PBS, pH 7.3, followed by $10 \%$ formalin in $0.1 \mathrm{M} \mathrm{PB}$, and the same buffer containing $10 \%$ sucrose and then $30 \%$ sucrose. The brains were removed and kept in $0.1 \mathrm{M}$ PBS containing $30 \%$ sucrose at $4^{\circ} \mathrm{C}$, and then cut serially into $60-\mu \mathrm{m}$-thick frontal sections on a freezing microtome. These sections were mounted onto gelatin-coated glass slides and stained with $1 \%$ Neutral Red. The recording and drug injection sites were reconstructed according to the lesions made by current injections and the traces of the electrode tracks. 
Table 2. STN Neuronal responses evoked by stimulation of the M1 and SMA

\begin{tabular}{|c|c|c|c|c|c|c|c|c|}
\hline \multirow[b]{2}{*}{ Cortical stimulating site } & \multicolumn{3}{|l|}{ Latency (ms) } & \multicolumn{3}{|l|}{ Duration (ms) } & \multicolumn{2}{|c|}{ Amplitude (spikes) } \\
\hline & Early excitation & Gap & Late excitation & Early excitation & Gap & Late excitation & Early excitation & Late excitation \\
\hline M1 $(n=47)$ & $5.4 \pm 1.4^{* *}$ & $13.4 \pm 2.8$ & $16.8 \pm 4.1$ & $8.0 \pm 4.2$ & $3.3 \pm 2.8^{* *}$ & $22.9 \pm 11.1$ & $84.0 \pm 63.1^{*}$ & $241.9 \pm 199.6$ \\
\hline
\end{tabular}

Data are the mean \pm SD of latencies, durations, and amplitudes of each response component (early excitation, gap, and late excitation) in the STN evoked by stimulation of the forearm regions of the M1 and the SMA. In M1 + SMA recipient STN neurons, the biphasic response with larger amplitude was used.

${ }^{*} p<0.01,{ }^{* *} p<0.001$, significantly different from each other between M1 and SMA stimulation, one-tailed unpaired $t$ test.

A
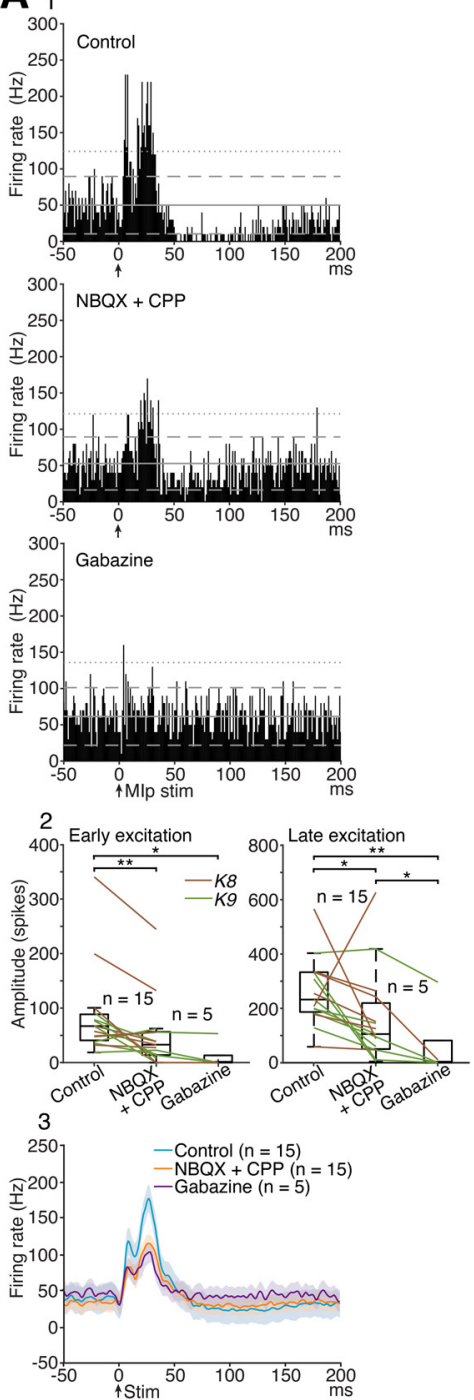

B
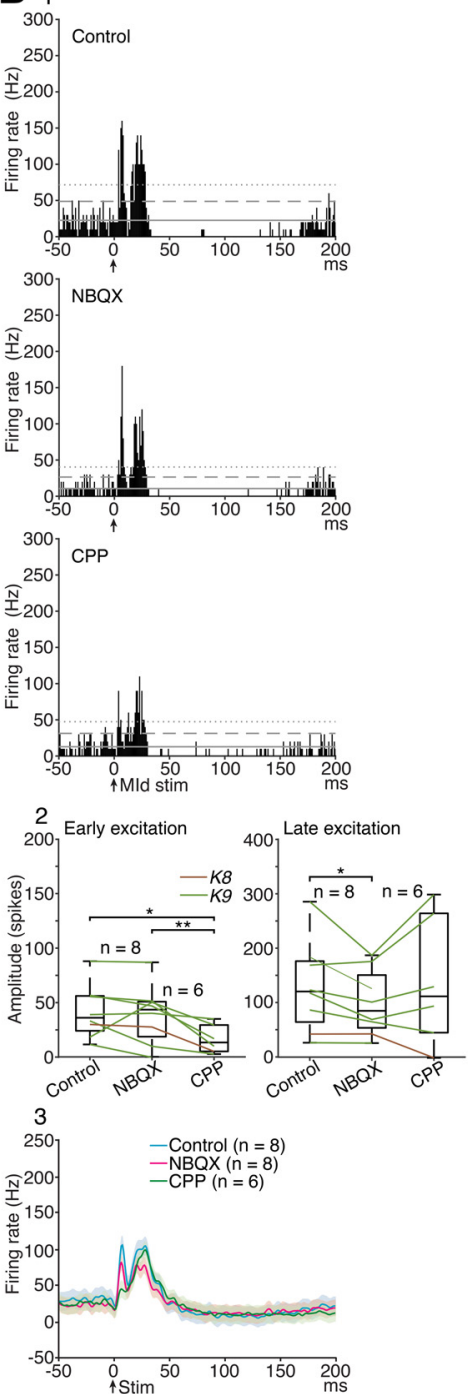

C
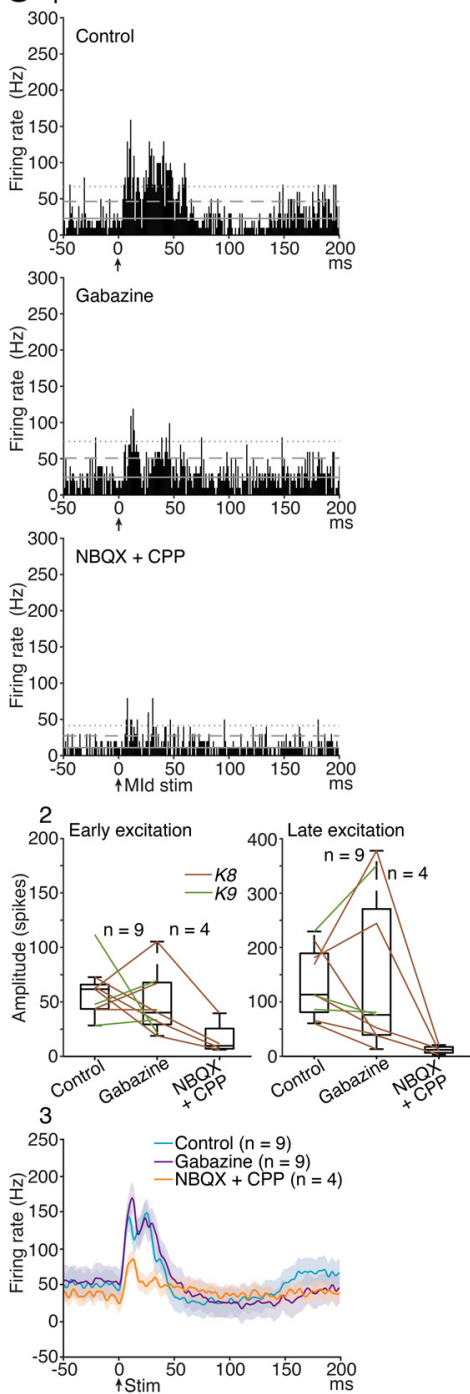

Figure 3. Cortically evoked responses of STN neurons before and after local drug injections in the vicinity of recorded neurons. A-C, The following drugs were injected: NBQX + CPP and then gabazine $(\boldsymbol{A})$; NBQX and then CPP (B); gabazine and then NBQX + CPP (C). $\boldsymbol{A 1}, \mathbf{B 1}, \mathbf{C 1}$, PSTHs in response to cortical stimulation [arrow with M1p or M1d stim, single-pulse, $0.5 \mathrm{~mA}$, 100 times] in three STN neurons before and after drug injection. $\mathbf{A 2}, \mathbf{B 2}, \mathbf{C}$, Box plots (the median, first and third quartiles, and the minimum and maximum excluding any outliers outside 1.5 times the interquartile range from the upper and lower quartiles) of amplitudes of early and late excitation before and after drug injections. Brown (Monkey K8) and green (Monkey K9) lines represent the amplitude of each neuron. ${ }^{*} p<0.05,{ }^{* *} p<0.01$, one-tailed paired $t$ test. A3, B3, C3, Population PSTHs of STN neurons before (cyan) and after NBQX + (PPP (orange), NBQX (magenta), CPP (green), or gabazine (purple) injection. The light-shaded colors represent $\pm \mathrm{SD}$.

\section{Results}

\section{Overview of recorded STN neurons}

A total of 158 STN neurons that showed a biphasic response to at least one of cortical stimulation were recorded (79 neurons in Monkey K8; 79 neurons in Monkey K9), and drug injections were performed in 91 STN neurons (see Materials and Methods). Among them, 70 STN neurons with good isolation throughout recordings before, during, and after drug injections were selected and analyzed as follows: STN injection, 33 neurons; Put injection, 15 neurons; GPe injection, 22 neurons (Table 1). The spontaneous firing rate of these STN neurons before drug injection was $34.4 \pm 16.9 \mathrm{~Hz}$ (mean \pm SD).

Cortical stimulation evoked a biphasic response composed of early excitation (Fig. $2 A 1, A 2{ }^{*}$ ) and late excitation (Fig. $2 A 1, A 2$, ${ }^{\star *}$ ), with an intervening short gap (Fig. $2 A 1, A 2, \boldsymbol{\nabla}$ ), in STN neurons, and they were classified into $36 \mathrm{M} 1$-recipient neurons 
Table 3. Effects of local drug injections on cortically evoked responses and spontaneous activity of STN neurons

\begin{tabular}{|c|c|c|c|c|c|c|c|c|c|}
\hline & $\begin{array}{l}\text { Control } \\
(n=15)\end{array}$ & $\begin{array}{l}\mathrm{NBQX}+\mathrm{CPP} \\
(n=15)\end{array}$ & $\begin{array}{l}\text { Gabazine } \\
(n=5)\end{array}$ & $\begin{array}{l}\text { Control } \\
(n=8)\end{array}$ & $\begin{array}{l}\mathrm{NBQX} \\
(n=8)\end{array}$ & $\begin{array}{l}\text { CPP } \\
(n=6)\end{array}$ & $\begin{array}{l}\text { Control } \\
(n=9)\end{array}$ & $\begin{array}{l}\text { Gabazine } \\
(n=9)\end{array}$ & $\begin{array}{l}\overline{N B Q X}+\mathrm{CPP} \\
(n=4)\end{array}$ \\
\hline \multicolumn{10}{|l|}{ Cortically evoked responses } \\
\hline \multicolumn{10}{|l|}{ Early excitation } \\
\hline Duration (ms) & $9.1 \pm 4.9$ & $6.7 \pm 6.1^{*}$ & $1.0 \pm 2.2$ & $6.6 \pm 2.4$ & $6.1 \pm 3.9$ & $4.8 \pm 2.9$ & $10.0 \pm 5.2$ & $9.1 \pm 4.8$ & $8.0 \pm 3.4$ \\
\hline \multicolumn{10}{|l|}{ Late excitation } \\
\hline Amplitude (spikes) & $261.1 \pm 123.6$ & $161.9 \pm 168.7^{*}$ & $61.3 \pm 131.4^{*}$ & $153.7 \pm 82.8$ & $123.7 \pm 59.1^{*}$ & $162.5 \pm 118.6$ & $150.2 \pm 63.4$ & $154.9 \pm 143.2$ & $25.2 \pm 7.4$ \\
\hline Amplitude (spikes) & $4.8 \pm 7.6$ & $5.5 \pm 4.5$ & $1.0 \pm 0.9^{*}$ & $6.6 \pm 4.8$ & $7.1 \pm 4.4$ & $6.2 \pm 3.8$ & $3.9 \pm 7.3$ & $5.5 \pm 7.7$ & $7.6 \pm 6.4$ \\
\hline Duration (ms) & $2.5 \pm 2.1$ & $4.6 \pm 2.9^{*}$ & $3.0 \pm 1.3$ & $5.3 \pm 3.3$ & $6.0 \pm 2.4$ & $6.0 \pm 1.8$ & $2.0 \pm 2.3$ & $4.0 \pm 4.7$ & $6.5 \pm 7.0$ \\
\hline \multicolumn{10}{|l|}{ Spontaneous activity } \\
\hline Firing rate $(\mathrm{Hz})$ & $38.8 \pm 11.4$ & $32.6 \pm 9.7^{*}$ & $43.0 \pm 15.3$ & $27.7 \pm 17.5$ & $23.7 \pm 10.1$ & $21.9 \pm 19.3$ & $37.4 \pm 21.0$ & $47.3 \pm 31.2^{*}$ & $34.4 \pm 29.7$ \\
\hline $\mathrm{Bl}$ & $2.50 \pm 2.13$ & $4.23 \pm 5.40$ & $6.64 \pm 6.53$ & $2.22 \pm 0.51$ & $2.52 \pm 0.82$ & $3.76 \pm 2.31$ & $1.62 \pm 0.73$ & $1.74 \pm 0.87$ & $4.64 \pm 1.86$ \\
\hline CV of ISIs & $1.10 \pm 0.64$ & $1.58 \pm 1.04$ & $1.90 \pm 1.58^{* *}$ & $1.33 \pm 0.94$ & $1.18 \pm 0.64$ & $1.28 \pm 0.57$ & $1.29 \pm 1.37$ & $1.08 \pm 1.08$ & $1.43 \pm 0.53$ \\
\hline
\end{tabular}

Data are the mean \pm SD of amplitudes and durations of cortically evoked early excitation, late excitation, and gaps, and firing rate, BI, and CV of ISIs in STN neurons ( $n$ represents the number of neurons examined). Different drugs were applied in different orders in the vicinity of recorded STN neurons.

${ }^{*} p<0.05$, ${ }^{* *} p<0.01$, significantly different from the adjacent column on the left, one-tailed paired $t$ test. §Amplitude and duration of the gap were not calculated in all STN neurons because decreased late excitation made defining the gap difficult.
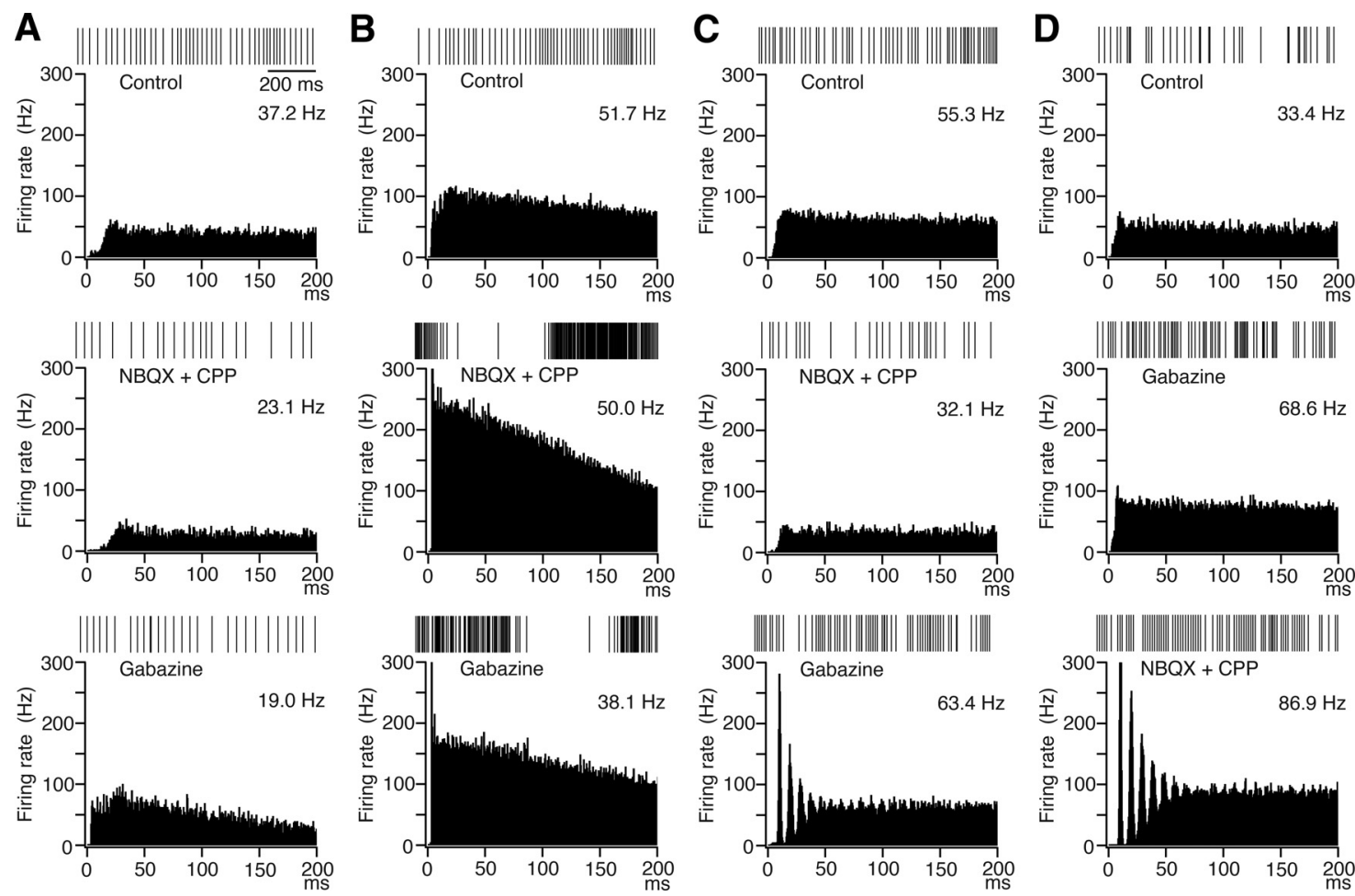

Figure 4. Spontaneous activity of four STN neurons before and after drug injections in the vicinity of recorded neurons. Digitized spikes (top) and autocorrelograms (bottom) of spontaneous activity, and spontaneous firing rates (in Hz) are shown. $\boldsymbol{A}-\boldsymbol{D}$, The following drugs were injected: NBQX + (PP and then gabazine ( $\boldsymbol{A}-\boldsymbol{C})$, gabazine and then NBQX + (PP (D).

(51\%; responded to M1, but not to SMA stimulation), 23 SMArecipient neurons (33\%; responded to SMA, but not to M1 stimulation), and 11 M1 + SMA-recipient neurons (16\%; responded to both M1 and SMA stimulation). Latencies, durations, and amplitudes of early excitation, gap, and late excitation were compared between M1 and SMA stimulation (Table 2). The latency of each component agreed well with previously reported data (Nambu et al., 2000; Iwamuro et al., 2017). The latency of early excitation evoked by M1 stimulation was significantly shorter than that evoked by SMA stimulation $\left(t_{(68)}=7.31, p=1.97 \times\right.$ $10^{-10}$; one-tailed unpaired $t$ test). The duration of the gap was shorter $\left(t_{(68)}=3.74, p=1.89 \times 10^{-4}\right)$, and the amplitude of early excitation was larger $\left(t_{(68)}=2.84, p=0.003\right)$ in M1 stimulation than in SMA stimulation. On the other hand, the durations of early and late excitation were comparable between M1 and SMA stimulation. In the following drug injection experiments, durations and amplitudes obtained by M1 and SMA stimulation were grouped together and analyzed. In $70 \%$ of cases, this biphasic response was followed by long-lasting late inhibition (Fig. 2A1, A2, $\nabla \nabla$; latency, 40-70 ms; duration, 40-200 ms).

We also observed STN responses evoked by stimulation in the Put and GPe. Put stimulation evoked excitation in 15 STN neurons among 20 neurons tested (Fig. $2 B$ ) probably by the disinhibition through the Put-GPe-STN pathway, and excitation 
A
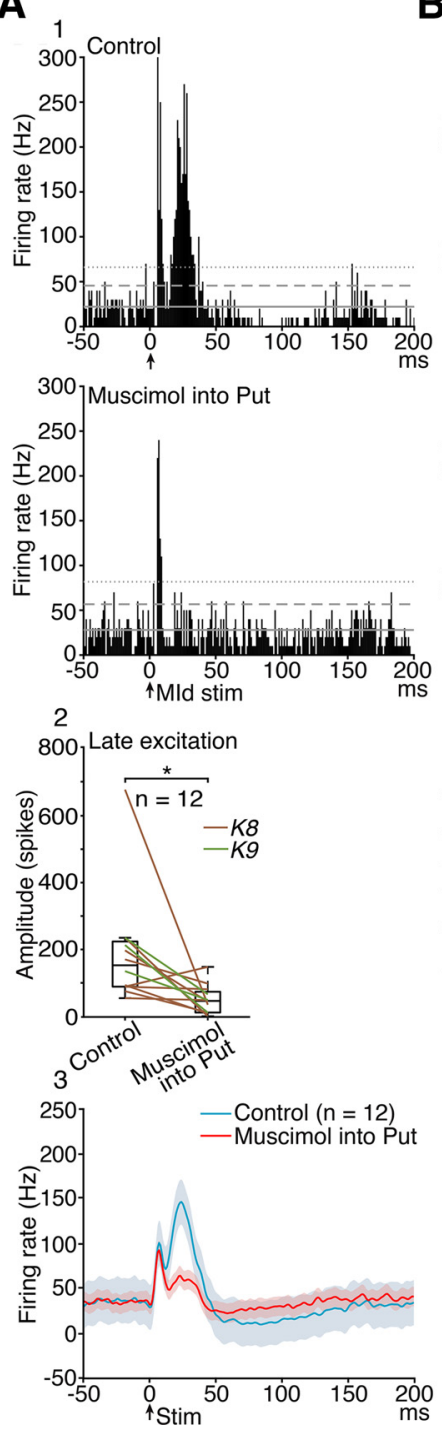

B
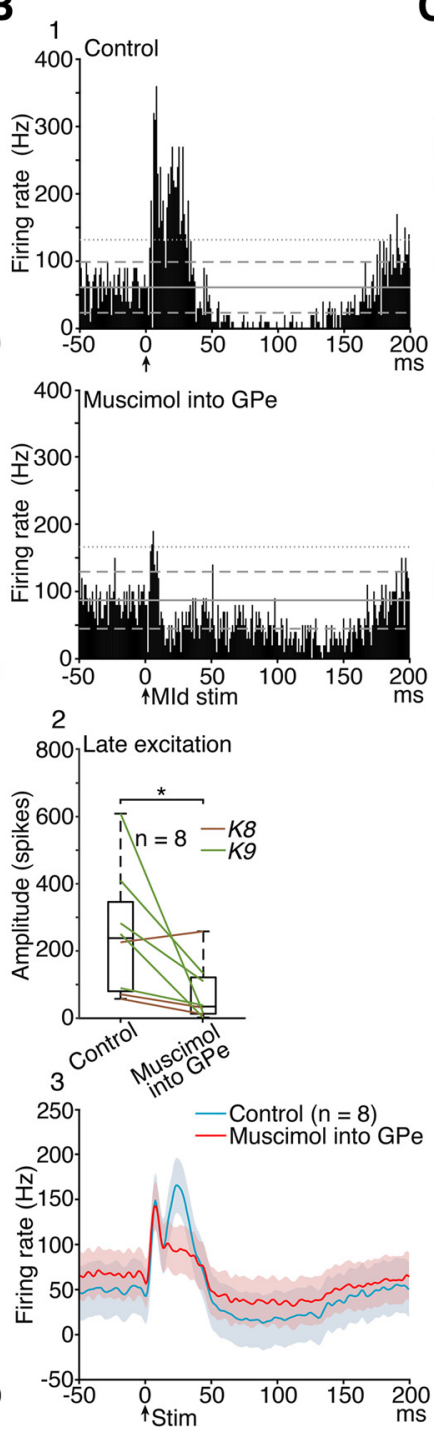

C
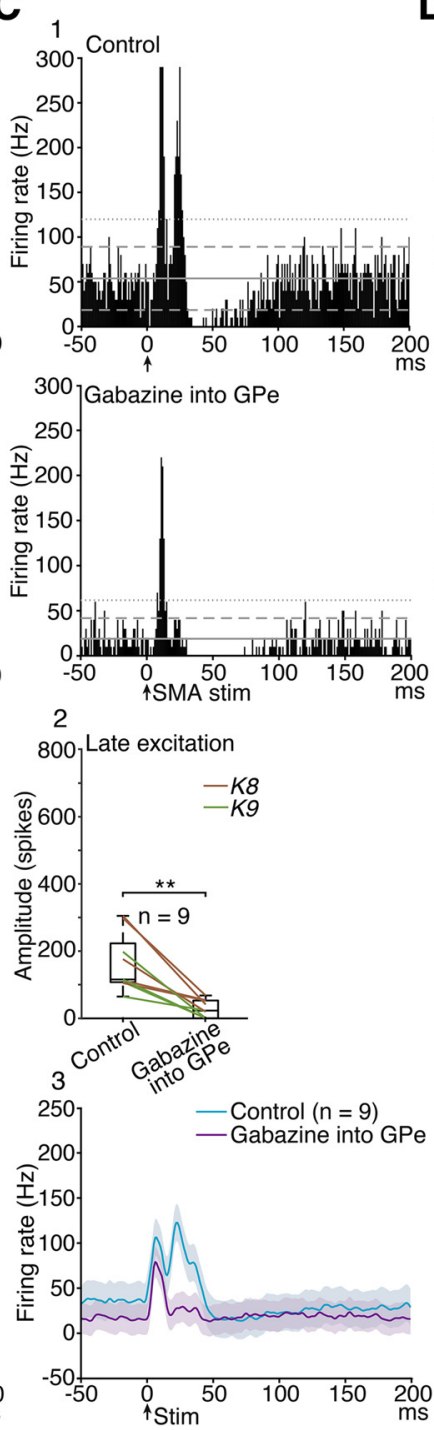
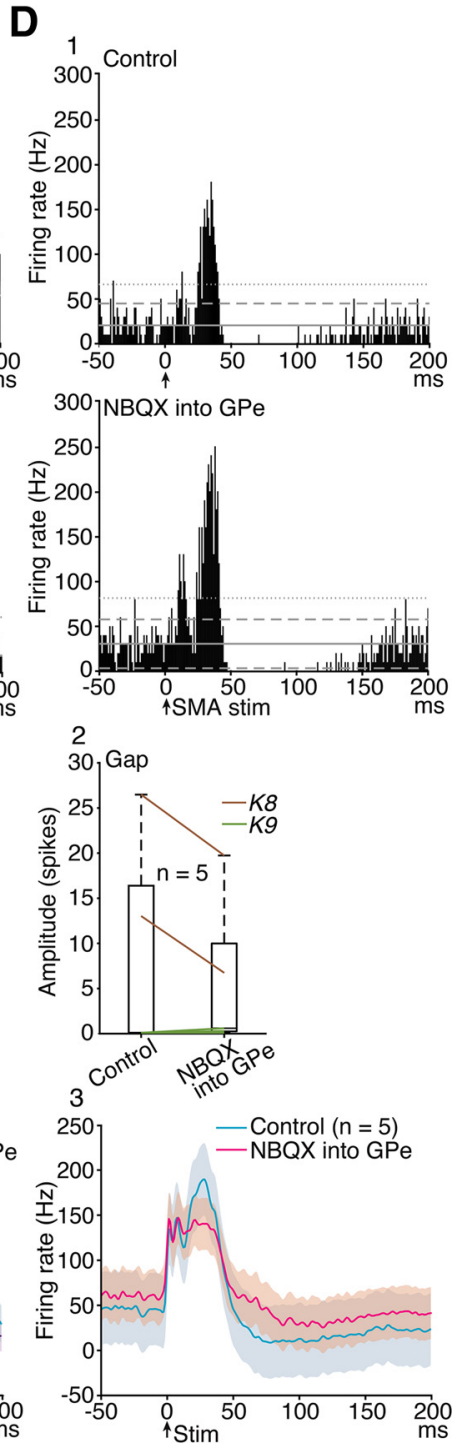

Figure 5. Cortically evoked responses of STN neurons before and after drug injections into the Put or GPe. $\boldsymbol{A}-\boldsymbol{D}$, The following drugs were injected: muscimol into the Put (A); muscimol into the GPe $(\boldsymbol{B})$; gabazine into the GPe (C); NBQX into the GPe (D). $\boldsymbol{A} 1, \boldsymbol{B 1}, \mathbf{C 1}, \mathbf{D 1}$, PSTHs in response to cortical stimulation (M1d or SMA stim, $0.5 \mathrm{~mA}, 100$ times) before and after drug injections. A2, B2, C2, D2, Box plots (the median, first and third quartiles, and minimum and maximum excluding any outliers) of amplitudes of late excitation $(\boldsymbol{A 2}, \mathbf{B 2}, \mathbf{C 2})$ or the gap (D2) before and after drug injections. Brown (Monkey K8) and green (Monkey K9) lines represent the amplitude of each neuron. ${ }^{*} p<0.05$, ${ }^{* *} p<0.01$, one-tailed paired $t$ test. A3, B3, C3, D3, Population PSTHs of STN neurons before (cyan) and after drug injections of muscimol (red), gabazine (purple), or NBQX (magenta). The light-shaded colors represent $\pm S D$.

was usually followed by weak inhibition (12 of 15 neurons). Latencies of excitation and inhibition were $4.6 \pm 2.4$ and $37.8 \pm 14.6 \mathrm{~ms}$, respectively. GPe stimulation evoked inhibition in 36 STN neurons among 39 neurons tested (Fig. 2C) through the GPe-STN GABAergic inhibitory projection, and inhibition was usually followed by excitation ( 28 of 36 neurons). Inhibition began just after the stimulation artifacts, and excitation began at a latency of $12.7 \pm 4.1 \mathrm{~ms}$. We observed no antidromic responses in STN neurons to GPe stimulation in this study. The latency of Put-evoked disinhibition $(4.6 \mathrm{~ms})$ is compatible with the conduction time of the Put-GPe (3-9 ms; Yoshida et al., 1993) and GPeSTN ( 1 ms; Fig. 2C; Nambu et al., 2000) GABAergic inhibitory projections.

\section{Drug injection in the vicinity of recorded STN neurons}

NBQX, CPP, and/or gabazine were applied in the vicinity of 33 STN neurons in various combinations and sequences (Table 1).
The mixture of NBQX and CPP (NBQX + CPP) was applied in 15 STN neurons to examine the contribution of glutamatergic inputs through ionotropic receptors on cortically evoked responses (Fig. 3A). Both early and late excitation were suppressed after NBQX + CPP injection (Fig. 3A1, middle). Quantitative analyses showed that the amplitude and duration of early excitation (by $42 \%$ : $t_{(14)}=3.51, p=1.7 \times 10^{-3}$, one-tailed paired $t$ test; by $26 \%: t_{(14)}=2.16, p=0.024$; respectively), and the amplitude of late excitation (by $38 \%: t_{(14)}=1.96, p=0.035$ ) evoked by cortical stimulation were significantly decreased after NBQX + CPP injection (Fig. 3A2; Table 3). These changes similarly occurred in both monkeys (Fig. 3A2). The duration of the gap between early and late excitation was increased (by 84\%: $t(12)=2.3, p=0.02$, one-tailed paired $t$ test; Table 3$)$. These changes were also observed in population PSTHs (Fig. 3A3). The results suggest that early and late excitation are related to glutamatergic inputs.

Next, to examine which drug, NBQX or CPP, effectively suppresses early and late excitation, we applied NBQX and CPP 
Table 4. Effects of drug injections into the Put or GPe on cortically evoked responses and spontaneous activity of STN neurons

\begin{tabular}{|c|c|c|c|c|c|c|c|c|}
\hline & \multicolumn{2}{|c|}{ Injection into the Put } & \multicolumn{6}{|c|}{ Injections into the GPe } \\
\hline & $\begin{array}{l}\text { Control } \\
(n=12)\end{array}$ & Muscimol & $\begin{array}{l}\text { Control } \\
(n=8)\end{array}$ & Muscimol & $\begin{array}{l}\text { Control } \\
(n=9)\end{array}$ & Gabazine & $\begin{array}{l}\text { Control } \\
(n=5)\end{array}$ & NBQX \\
\hline Amplitude (spikes) & $52.1 \pm 41.2$ & $44.5 \pm 34.9$ & $74.7 \pm 64.7$ & $46.5 \pm 49.2$ & $63.4 \pm 58.5$ & $51.4 \pm 50.1$ & $85.5 \pm 70.9$ & $85.0 \pm 43.4$ \\
\hline Duration (ms) & $6.3 \pm 2.8$ & $6.0 \pm 3.6$ & $6.8 \pm 2.6$ & $5.4 \pm 2.2$ & $6.3 \pm 2.1$ & $6.6 \pm 1.7$ & $7.0 \pm 3.2$ & $9.0 \pm 1.2$ \\
\hline Duration (ms) & $18.7 \pm 6.9$ & $9.3 \pm 6.0^{* *}$ & $21.1 \pm 12.3$ & $9.6 \pm 6.4^{*}$ & $15.6 \pm 7.0$ & $10.4 \pm 10.5^{* *}$ & $22.4 \pm 11.4$ & $19.6 \pm 6.4$ \\
\hline Gap & & $(n=10) \S$ & & $(n=7) \S$ & & $(n=6) \S$ & & \\
\hline Amplitude (spikes) & $14.5 \pm 15.0$ & $15.6 \pm 16.7$ & $10.2 \pm 8.9$ & $11.5 \pm 7.7$ & $11.6 \pm 7.7$ & $6.8 \pm 1.3$ & $8.0 \pm 11.8$ & $5.5 \pm 8.4$ \\
\hline Duration (ms) & $5.9 \pm 5.1$ & $6.6 \pm 4.4$ & $6.5 \pm 3.7$ & $7.4 \pm 3.7$ & $6.0 \pm 3.0$ & $9.2 \pm 3.8^{*}$ & $6.8 \pm 9.7$ & $4.8 \pm 7.1$ \\
\hline \multicolumn{9}{|l|}{ Spontaneous activity } \\
\hline Firing rate $(\mathrm{Hz})$ & $30.1 \pm 16.7$ & $24.3 \pm 15.2$ & $48.6 \pm 23.2$ & $61.6 \pm 23.9^{*}$ & $31.1 \pm 20.4$ & $11.5 \pm 10.2^{* *}$ & $33.1 \pm 16.0$ & $44.9 \pm 25.5$ \\
\hline
\end{tabular}

Data are the mean \pm SD of amplitudes and durations of cortically evoked early excitation, late excitation, and gaps, and firing rate, BI, and CV of ISIs in STN neurons before and after the injection of muscimol, gabazine, or NBQX into the Put or GPe.

${ }^{*} p<0.05,{ }^{* *} p<0.01$, significantly different from control, one-tailed paired $t$ test. §Amplitude and duration of the gap were not calculated in all STN neurons because decreased late excitation made defining the gap difficult.

separately in the vicinity of STN neurons (Table 1; Fig. 3B). NBQX was applied in eight STN neurons (Fig. 3B1, middle). The amplitude of late excitation was significantly decreased after NBQX injection (by 20\%:\& $t_{(7)}=2.38, p=0.024$, one-tailed paired $t$ test), but no changes were observed in early excitation (Fig. 3B2; Table 3). CPP was additionally applied in six STN neurons (Fig. 3B1, bottom). The amplitude of early excitation was decreased after CPP injection (by $57 \% ; t_{(5)}=3.77, p=6.5 \times 10^{-3}$, one-tailed paired $t$ test; Fig. 3B2; Table 3 ). These changes similarly occurred in both monkeys (Fig. 3B2). They are also observed in population PSTHs: NBQX had a little effect on early excitation, whereas additional CPP application diminished early excitation (Fig. 3B3). When the drugs were injected in the reverse order (CPP and then NBQX) in one case, CPP specifically suppressed early excitation (data not shown). These results suggest that NMDA receptors have stronger effects on early excitation than AMPA/kainate receptors.

Additional gabazine injection was performed after NBQX + CPP injection in five STN neurons (Fig. $3 A 1$, bottom). The amplitude, but not the duration of late excitation, was significantly decreased after gabazine injection (by 62\%: $t_{(4)}=2.67, p=0.028$, one-tailed paired $t$ test; Fig. $3 A 2, A 3$; Table 3$)$, and the amplitude of the gap was decreased (by $82 \%: t_{(4)}=2.49, p=0.034$ ). When gabazine was injected first (before NBQX + CPP injection; reverse order; Fig. 3C1, middle), no significant change was detected in early excitation, the gap, or late excitation (Fig. 3C2, C3; Table 3). Additional NBQX + CPP injection (Fig. 3C1, bottom) showed a tendency to decrease both early and late excitation (not statistically tested because only four neurons were recorded; Fig. 3C2,C3; Table 3).

We also examined the effects of local drug injections on spontaneous firing rates and patterns of STN neurons (Table 3; Fig. 4). After NBQX + CPP injection, the spontaneous firing rate was decreased (by 16\%: $t_{(14)}=2.35, p=0.017$, one-tailed paired $t$ test), but was not changed after additional gabazine injection (Table 3). The spontaneous firing rate was not changed following separate injection of NBQX or CPP. After gabazine injection without NBQX and CPP, the spontaneous firing rate was increased (by 26\%: $t_{(8)}=2.73, p=0.013$, one-tailed paired $t$ test), but was not changed after additional injection of NBQX + CPP (Table 3). These results suggest that spontaneous firing rates were continuously controlled by AMPA/kainate and NMDA glutamatergic, and GABAergic inputs. We found no significant changes in other parameters of STN spontaneous neuronal activity, except for an increase in the CV of ISIs after additional gabazine injection after NBQX + CPP injection (by 20\%: $t_{(4)}=3.97$, $p=0.008$, one-tailed paired $t$ test; Table 3 ). No significant change in the spontaneous firing pattern was observed after local drug injections in autocorrelograms (Fig. 4A), except for the following seven cases: bursts and pauses appeared in three STN neurons after NBQX + CPP injection (Fig. $4 B$ ) or after NBQX + CPP and gabazine injection, and oscillations appeared in four STN neurons (Fig. 4C,D; oscillatory periods, $\sim 9-10 \mathrm{~ms}$ ) after both NBQX $+\mathrm{CPP}$ and gabazine injection.

\section{Drug injection into the Put}

The above experiments of local drug injection into the STN showed that additional gabazine injection after NBQX + CPP injection diminished late excitation, suggesting that cortically evoked late excitation is related to GABAergic inputs mediated by the Put-GPe-STN indirect pathway. To examine this possibility, we blocked Put activity by injecting muscimol into the Put (Table 1; Fig. 5A). Muscimol injection diminished cortically evoked late excitation in the STN (Fig. 5A1). The amplitude and duration of late excitation were significantly decreased after muscimol injection (by 74\%: $t_{(11)}=2.66, p=0.011$, one-tailed paired $t$ test; by $50 \%: t_{(11)}=4.2, p=0.75 \times 10^{-3}$; respectively; Fig. $5 A 2, A 3$; Table 4 ), whereas those of early excitation remained unchanged. The spontaneous firing rate and pattern of STN neurons were also examined before and after drug injections. The firing rate, $\mathrm{BI}$, and $\mathrm{CV}$ of ISIs did not change after muscimol injection (Table 4). These data support the idea that cortically evoked late excitation is mediated by the Put-GPe-STN indirect pathway.

\section{Drug injection into the GPe}

We then blocked the Put-GPe-STN indirect pathway by injection of muscimol or gabazine into the GPe (Table 1; Fig. $5 B, C$ ). We first injected muscimol into the GPe to block GPe activity (Fig. $5 B$ ). Muscimol injection decreased cortically evoked late excitation in the STN (Fig. 5B1). The amplitude and duration of late 

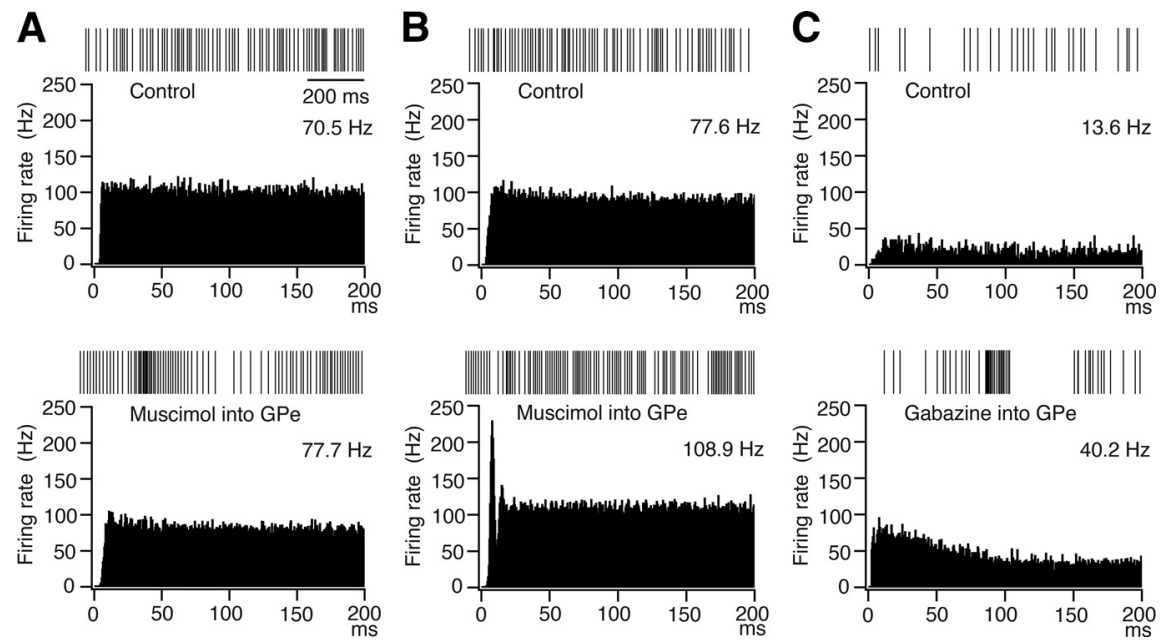

Figure 6. Spontaneous activity of three STN neurons before and after drug injections into the GPe. Digitized spikes (top) and autocorrelograms (bottom) of spontaneous activity, and spontaneous firing rates (in $\mathrm{Hz}$ ) are shown. $\boldsymbol{A}-\boldsymbol{C}$, The following drugs were injected: muscimol $(\boldsymbol{A}, \boldsymbol{B})$; gabazine $(\boldsymbol{C})$.

\section{A}
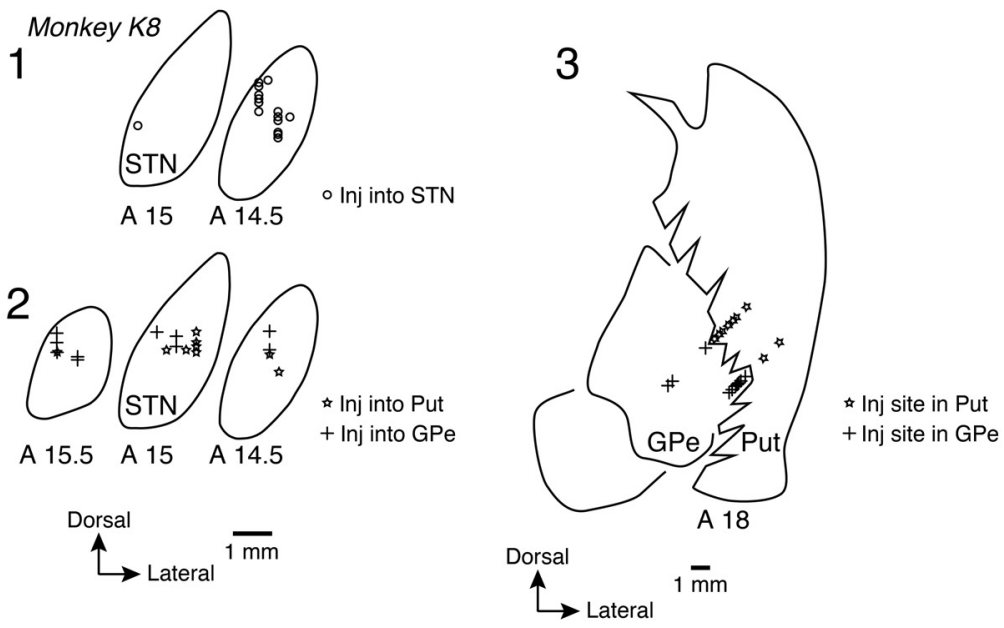

B

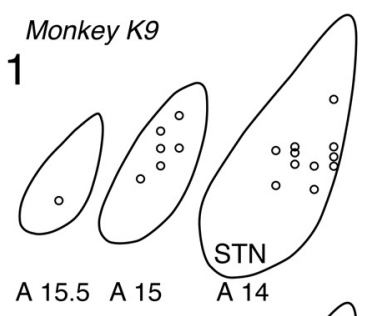

2
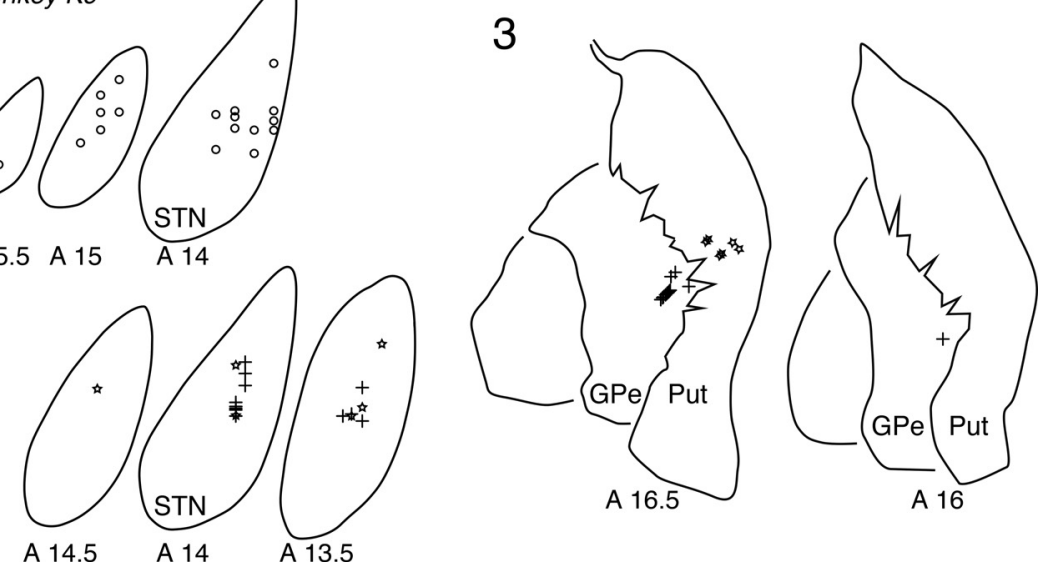

Figure 7. $\boldsymbol{A}, \boldsymbol{B}$, Locations of recorded STN neurons and drug injection sites in the Put and GPe in Monkey K8 (left hemisphere, flipped horizontally; $\boldsymbol{A}$ ) and Monkey $\mathrm{K9}$ (right hemisphere; $\boldsymbol{B}$ ). A1, B1, Locations of recorded STN neurons with drug injections in the vicinity of recorded neurons (circles). A2, B2, Locations of recorded STN neurons with drug injections into the Put (stars) or GPe (crosses). A3, B3, Locations of the corresponding drug injection sites in the Put (stars) and GPe (crosses). The distance of the sections from the auditory meatus is shown (in $\mathrm{mm}$ ) beneath each section. excitation were significantly decreased after muscimol injection (by $71 \%: t_{(7)}=2.45$, $p=0.022$, one-tailed paired $t$ test; by $55 \%$ : $t_{(7)}=2.28, p=0.028$; respectively; Fig. 5B2, B3; Table 4), whereas those of early excitation remained unchanged. The spontaneous firing rate of STN neurons was significantly increased after muscimol injection (by 27\%: $t_{(7)}=2.45, p=0.022$, one-tailed paired $t$ test; Table 4$)$. No significant change in BI or CV of ISIs was observed after muscimol injection. However, analyses of individual neurons showed pattern changes, such as the appearance of bursts in two STN neurons (Fig. 6A) and increased regularity in three STN neurons (Fig. 6B).

We separately injected gabazine into the GPe to block Put-GPe GABAergic neurotransmission (Fig. 5C). Gabazine injection decreased cortically evoked late excitation in the STN (Fig. 5C1). The amplitude and duration of late excitation were significantly decreased after gabazine injection (by $83 \%$ : $t_{(8)}=5.05, p=0.49 \times 10^{-3}$, one-tailed paired $t$ test; by $33 \%$ : $t_{(8)}=3.19, p=6.4 \times 10^{-3}$; respectively; Fig. 5C2,C3; Table 4), whereas those of early excitation remained unchanged. The duration of the gap was increased after gabazine injection (by $53 \%$ : $t_{(5)}=2.63, p=0.023$, one-tailed paired $t$ test). The spontaneous firing rate of STN neurons was significantly decreased after gabazine injection (by 63\%: $t_{(8)}=3.14$, $p=0.007$, one-tailed paired $t$ test; Table 4 ). BI (by $352 \%$ : $t_{(8)}=2.76, p=0.012$, one-tailed paired $t$ test), and the CV of ISIs (by $45 \%$ : $\left.t_{(8)}=2.47, p=0.019\right)$ were increased after gabazine injection (Table 4). Bursts were observed in three STN neurons (Fig. 6C).

The GPe also receives glutamatergic inputs from the STN. Cortical stimulation evokes early excitation in the GPe through the cortico-STN-GPe glutamatergic projections (Nambu et al., 2000), and this early excitation can be blocked by local injection of NBQX into the GPe (Kita et al., 2004). NBQX injection into the GPe did not change significantly cortically evoked early or late excitation, or the gap between them in the STN (Fig. 5D1-D3; Table 4). The spontaneous firing rate and pattern were not changed after NBQX injection (Table 4).

\section{Other findings}

The cortically evoked biphasic response was usually followed by long-lasting late inhibition in STN neurons (Figs. $2 A ; 3 A 1, B 1$, top; $5 A 1, B 1, C 1, D 1$, upper). The amplitude of long-lasting late inhibition was not changed after gabazine injection into the STN (control, 388.2 \pm 258.2 spikes; after gabazine, $423.2 \pm 355.7$ spikes; $n=9$; Fig. 


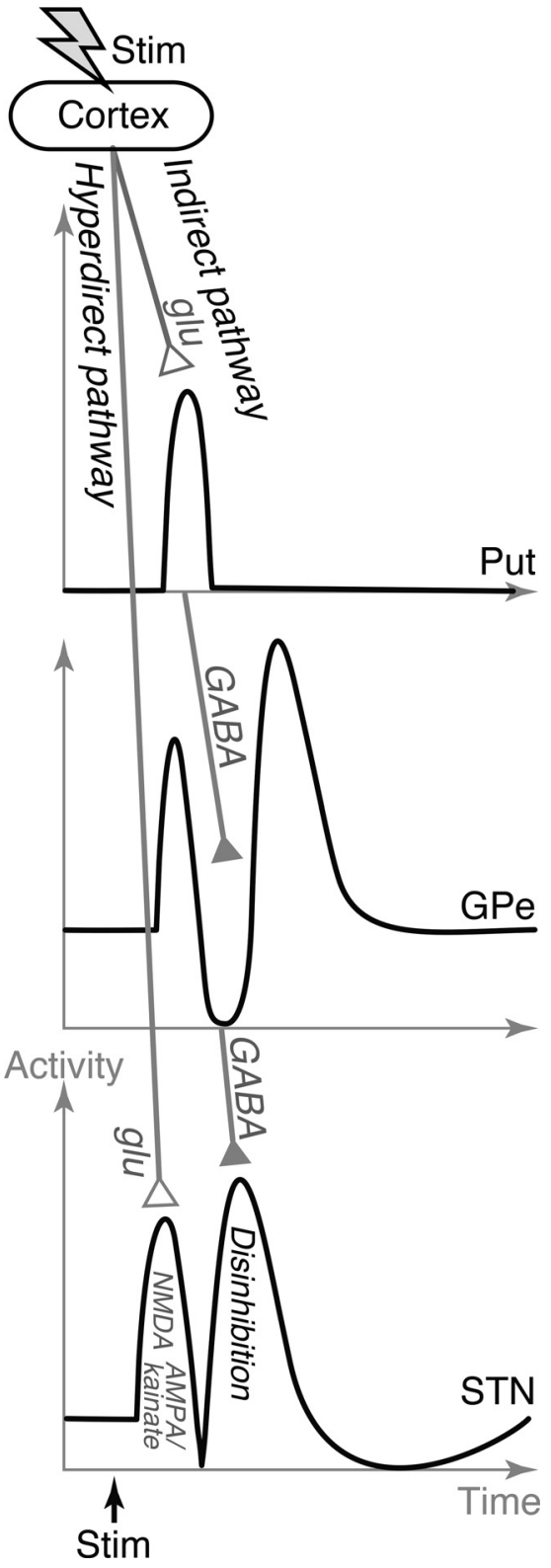

Figure 8. Summary diagram explaining the origin of cortically evoked early excitation and late excitation in the STN. Early excitation is mediated by direct excitatory inputs from the cerebral cortex through the cortico-STN hyperdirect pathway. On the other hand, late excitation is caused by a disinhibitory process from the GPe through the cortico-Put-GPe-STN indirect pathway.

$3 C 3)$ or after muscimol injection into the GPe (control, $359.1 \pm 303.9$ spikes; after muscimol, $417.2 \pm 271.3$ spikes; $n=8$; Fig. 5B3).

Although we did not pay much attention to behavioral changes after drug injections because it was not the objective of the present study, we noticed that muscimol injection into the GPe temporally decreased grasping ability in one case and that gabazine injection into the GPe induced abnormal dyskinetic movements in the wrist and/or hand in two cases.

\section{Locations of recorded STN neurons and drug injection sites in the Put and GPe}

The locations of recorded STN neurons, along with drug injection sites in the STN, Put, and GPe, were plotted in the two monkeys based on the histologic examination (Fig. 7). The recorded
STN neurons were found in the middle of the STN (Fig. 7A1,A2, $B 1, B 2)$, corresponding to M1-receiving and/or SMA-receiving forelimb regions (Iwamuro et al., 2017). Drug injection sites in the Put and GPe were found in the dorsoventral midpoints in the Put and GPe (Fig. 7A3,B3), corresponding to M1-receiving and/or SMA-receiving forelimb regions (Nambu et al., 2002a; Iwamuro et al., 2017).

\section{Discussion}

The following results were obtained (Fig. 8): (1) cortically evoked early excitation and late excitation in the STN are mediated by the cortico-STN glutamatergic hyperdirect and cortico-Put-GPeSTN indirect pathways, respectively; and (2) STN spontaneous activity is controlled by tonic glutamatergic and GABAergic inputs.

\section{Origin of early excitation}

Cortically evoked early excitation in the STN decreased after local NBQX + CPP injection (Fig. 3), suggesting that early excitation is mediated by ionotropic glutamatergic inputs (Fig. 8). Cortical stimulation induces strong synchronized inputs and evoked short-latency and short-duration excitation (Kitai and Deniau, 1981; Rouzaire-Dubois and Scarnati, 1987; Froux et al., 2018). However, a weak response remained after NBQX + CPP injection, probably because (1) other types of receptors, such as metabotropic glutamate receptors (Kuwajima et al., 2004; Galvan et al., 2006) may partly contribute; and (2) injected drugs may not entirely cover the large dendritic fields of STN neurons (Rafols and Fox, 1976; Afsharpour, 1985; Sato et al., 2000). Other pathways may also contribute to excitation in the STN. The pedunculopontine nucleus, which receives cortical inputs, sends glutamatergic and cholinergic projections to the STN (Lavoie and Parent, 1994; Bevan and Bolam, 1995; Kita and Kita, 2011). The centromedian/parafascicular thalamic nucleus also sends glutamatergic projections to the STN (Sadikot et al., 1992; Mouroux et al., 1995). Local NBQX + CPP injection into the STN may also block these glutamatergic inputs, but not cholinergic inputs.

Separate application of NBQX and CPP suggests a larger contribution of NMDA receptors than AMPA/kainate receptors (Fig. $3 B$ ). However, the numbers of neurons are limited and biased to one monkey (Table 1), and thus we would like to withhold the conclusion of the individual contributions of these receptors to early excitation. Previous studies reported both NMDA and AMPA/kainate receptors and excitatory responses mediated by both receptors in STN neurons (Clarke and Bolam, 1998; Wang et al., 2000; Smith et al., 2001; Farries et al., 2010; Chu et al., 2015, 2017; Swanger et al., 2015; Froux et al., 2018).

The latency of early excitation evoked by M1 stimulation is shorter than that evoked by SMA stimulation, probably because of faster conduction velocity of axons derived from the M1 than those from the SMA (Firmin et al., 2014). SMA-induced STN responses may be mediated by the SMA-M1-STN pathway; however, this is less probable because the distribution of SMA-recipient STN neurons does not completely overlap with that of M1-recipient neurons (Iwamuro et al., 2017).

\section{Origin of late excitation}

Blockade of the cortico-Put-GPe-STN pathway by muscimol injection into the Put/GPe or gabazine injection into the GPe (Kita et al., 2004) decreased cortically evoked late excitation in the STN (Fig. 5; see also Farries et al., 2010), suggesting that late 
excitation is caused by disinhibition from the GPe through the cortico-Put-GPe indirect pathway (Fig. 8). The latency of late excitation (Table 2) is compatible with the conduction time of the cortico-Put (10-14 ms; Nambu et al., 2000) and Put-GPe-STN (4.6 ms; Fig. 2) projections. A large volume of drugs was injected into the Put or GPe and might spread to neighboring structures. Gabazine or muscimol in the GPe might spread to the Put and increase (Darbin and Wichmann, 2008) or block Put activity, respectively. However, gabazine or muscimol had already blocked Put-GPe GABAergic transmission or GPe activity, and thus Put activity changes had no effects on STN activity. Muscimol injected into the Put might spread to the GPe, block GPe activity, and increase STN activity (Fig. 5B; Table 4). But, this is not the case because spontaneous STN activity was not increased after muscimol injection into the Put (Fig. 5A; Table 4).

On the other hand, local gabazine injection into the STN, which is expected to abolish continuous GABAergic inhibition from the GPe, did not always suppress cortically evoked late excitation (Fig. $3 A, C$ ), possibly because (1) other types of transmission, such as $\mathrm{GABA}_{\mathrm{B}}$ receptors in the STN (Charara et al., 1999; Galvan et al., 2004; Hallworth and Bevan, 2005), may also contribute to tonic inhibition and phasic disinhibition by the GPe; and (2) gabazine may not block all $\mathrm{GABA}_{\mathrm{A}}$ receptors.

Cortically evoked late excitation in the STN was suppressed after local NBQX + CPP or NBQX injection into the STN (Fig. $3 A-C)$. This is probably because excitability is decreased after injection, and disinhibition from the GPe could not effectively increase neuronal firing in the STN. Glutamatergic local axon collaterals of STN neurons may also amplify late excitation (Fujimoto and Kita, 1993; Gouty-Colomer et al., 2018).

\section{Origin of the gap}

Cortical stimulation induces early excitation in the GPe through the cortico-STN-GPe glutamatergic pathway (Kita, 1992; Nambu et al., 2000; Kita et al., 2004). The direct corticopallidal glutamatergic projection may also contribute to early excitation in the GPe (Karube et al., 2019; Abecassis et al., 2020). We examined whether this early excitation in the GPe induces the gap in the STN thorough GPe-STN GABAergic inhibitory transmission. Local gabazine injection into the STN or NBQX injection into the GPe did not decrease the gap (Figs. 3C, 5D; Tables 3, 4), and muscimol injection into the GPe did not increase early excitation (Fig. 5B; Table 4), suggesting that the gap is not likely because of active GABAergic inhibition from the GPe, but simply because of the absence of excitation. Injected NBQX into the GPe might spread to the Put, block cortico-Put glutamatergic transmission, and decrease late excitation in the STN, which is mediated by the cortico-Put-GPe-STN pathway (Fig. 5D).

\section{Origin of long-lasting late inhibition}

Cortically evoked long-lasting late inhibition in the STN may be caused by (1) disfacilitation from the cortex after stimulation, (2) GABAergic inhibition caused by late excitation in the GPe through the GPe-STN projection, and/or (3) a $\mathrm{Ca}^{2+}$-dependent $\mathrm{K}^{+}$current caused by strong late excitation. However, long-lasting late inhibition was not affected by local gabazine injection into the STN or muscimol injection into the GPe, suggesting that contribution of late excitation in the GPe is minor.

\section{Spontaneous activity changes}

Local NBQX + CPP application to STN neurons decreased spontaneous firing rates. On the other hand, local gabazine injection into the STN or muscimol injection into the GPe increased spontaneous firing rates. Thus, STN neuronal activity may be controlled by tonic glutamatergic inputs from the cortex and by tonic GABAergic inputs from the GPe. Firing patterns of STN neurons are resistant to drug manipulation in contrast to GPe/ GPi neurons (Kita et al., 2004, 2006; Tachibana et al., 2008), probably because STN neurons have intrinsic membrane properties that regulate their firing (Nakanishi et al., 1987; Farries et al., 2010; Wilson and Bevan, 2011). Similar strength of background glutamatergic and GABAergic inputs maintains the mean firing rates and makes firing patterns more irregular.

\section{Functional considerations}

Here we used electrical stimulation in the motor cortices, because cortical activity is likely to be similarly transmitted along the cortico-BG loop during voluntary movements. The STN receives cortical inputs and projects to the GPi/SNr. Cortical stimulation induces early excitation, inhibition, and late excitation in the GPi/SNr (Nambu et al., 2000; Kita et al., 2004; Tachibana et al., 2008), and early and late excitation in the STN induces early and late excitation in the GPi/SNr.

In fact, STN neurons increase their activity in relation to limb and eye movements (Georgopoulos et al., 1983; DeLong et al., 1985; Matsumura et al., 1992; Wichmann et al., 1994). Recent reports emphasized STN activity related to changes or cancellation of movements, because STN activity increases GPi activity, thereby decreasing the subsequent thalamocortical activity, and eventually suppresses movements (Nambu et al., 2000, 2002b; Aron and Poldrack, 2006; Isoda and Hikosaka, 2008; Schmidt et al., 2013; Pasquereau and Turner, 2017; Schmidt and Berke, 2017). We assume that STN activity during task performance is mediated by the short-latency cortico-STN hyperdirect and/or long-latency cortico-Put-GPe-STN indirect pathways.

Dyskinetic or choreic movements were observed after injection of GABA receptor antagonists into the GPe in the present and previous studies (Crossman et al., 1988; Grabli et al., 2004). In Huntington's disease, which typically shows chorea, striatoGPe projection neurons are more affected than striato-GPi neurons, particularly in its early stages (Reiner et al., 1988; Storey and Beal, 1993). Specific ablation of striato-GPe neurons diminishes cortically evoked late excitation in the $\mathrm{SNr}$ and induces locomotor hyperactivity in mice (Sano et al., 2013). STN lesion or blockade induces hemiballism in human patients and monkeys (Whittier and Mettler, 1949; Carpenter et al., 1950; Hamada and DeLong, 1992; Nambu et al., 2000). All these manipulations commonly block signals through the hyperdirect and/or indirect pathways, suggesting that these signals suppress or stop movements (Nambu et al., 2002b).

Lesions or chronic high-frequency stimulation (deep brain stimulation) in the STN ameliorates PD symptoms (Bergman et al., 1990; Aziz et al., 1991; Benabid et al., 1994; Limousin et al., 1995; Alvarez et al., 2005; Martínez-Fernández et al., 2018). These procedures affect all components in the STN, such as afferent inputs and STN neurons themselves, and detailed mechanisms remain to be elucidated. The present study provides basic knowledge of the STN functions in movement disorders and leads us to the development of new therapeutic strategies targeting the STN.

\section{References}

Abecassis ZA, Berceau BL, Win PH, García D, Xenias HS, Cui Q, Pamukcu A, Cherian S, Hernández VM, Chon U, Lim BK, Kim Y, Justice NJ, Awatramani R, Hooks BM, Gerfen CR, Boca SM, Chan CS (2020) 
$\mathrm{Npas}^{+}{ }^{+} \mathrm{-Nkx} 2.1^{+}$neurons are an integral part of the cortico-pallido-cortical loop. J Neurosci 40:743-768.

Afsharpour S (1985) Light microscopic analysis of Golgi-impregnated rat subthalamic neurons. J Comp Neurol 236:1-13.

Alexander GE, Crutcher MD (1990) Functional architecture of basal ganglia circuits: neural substrates of parallel processing. Trends Neurosci 13:266271.

Alonso-Frech F, Zamarbide I, Alegre M, Rodríguez-Oroz MC, Guridi J, Manrique M, Valencia M, Artieda J, Obeso JA (2006) Slow oscillatory activity and levodopa-induced dyskinesias in Parkinson's disease. Brain 129:1748-1757.

Alvarez L, Macias R, Lopez G, Alvarez E, Pavon N, Rodriguez-Oroz MC, Juncos JL, Maragoto C, Guridi J, Litvan I, Tolosa ES, Koller W, Vitek J, DeLong MR, Obeso JA (2005) Bilateral subthalamotomy in Parkinson's disease: initial and long-term response. Brain 128:570-583.

Aristieta A, Azkona G, Sagarduy A, Miguelez C, Ruiz-Ortega JA, SanchezPernaute R, Ugedo L (2012) The role of the subthalamic nucleus in LDOPA induced dyskinesia in 6-hydroxydopamine lesioned rats. PLoS One 7:e42652.

Aron AR, Poldrack RA (2006) Cortical and subcortical contributions to stop signal response inhibition: role of the subthalamic nucleus. J Neurosci 26:2424-2433.

Aziz TZ, Peggs D, Sambrook MA, Crossman AR (1991) Lesion of the subthalamic nucleus for the alleviation of 1-methyl-4-phenyl-1,2,3,6-tetrahydropyridine (MPTP)-induced parkinsonism in the primate. Mov Disord 6:288-292.

Benabid AL, Pollak P, Gross C, Hoffmann D, Benazzouz A, Gao DM, Laurent A, Gentil M, Perret J (1994) Acute and long-term effects of subthalamic nucleus stimulation in Parkinson's disease. Stereotact Funct Neurosurg 62:76-84.

Bergman H, Wichmann T, DeLong MR (1990) Reversal of experimental parkinsonism by lesions of the subthalamic nucleus. Science 249:1436-1438.

Bergman H, Wichmann T, Karmon B, DeLong MR (1994) The primate subthalamic nucleus. II. Neuronal activity in the MPTP model of parkinsonism. J Neurophysiol 72:507-520.

Bevan MD, Bolam JP (1995) Cholinergic, GABAergic, and glutamateenriched inputs from the mesopontine tegmentum to the subthalamic nucleus in the rat. J Neurosci 15:7105-7120.

Carpenter MB, Whittier JR, Mettler FA (1950) Analysis of choreoid hyperkinesia in the Rhesus monkey; surgical and pharmacological analysis of hyperkinesia resulting from lesions in the subthalamic nucleus of Luys. J Comp Neurol 92:293-331.

Charara A, Heilman TC, Levey AI, Smith Y (1999) Pre- and postsynaptic localization of $\mathrm{GABA}_{\mathrm{B}}$ receptors in the basal ganglia in monkeys. Neuroscience 95:127-140.

Chu HY, Atherton JF, Wokosin D, Surmeier DJ, Bevan MD (2015) Heterosynaptic regulation of external globus pallidus inputs to the subthalamic nucleus by the motor cortex. Neuron 85:364-376.

Chu HY, McIver EL, Kovaleski RF, Atherton JF, Bevan MD (2017) Loss of hyperdirect pathway cortico-subthalamic inputs following degeneration of midbrain dopamine neurons. Neuron 95:1306-1318.e5.

Clarke NP, Bolam JP (1998) Distribution of glutamate receptor subunits at neurochemically characterized synapses in the entopeduncular nucleus and subthalamic nucleus of the rat. J Comp Neurol 397:403-420.

Crossman AR, Mitchell IJ, Sambrook MA, Jackson A (1988) Chorea and myoclonus in the monkey induced by gamma-aminobutyric acid antagonism in the lentiform complex. The site of drug action and a hypothesis for the neural mechanisms of chorea. Brain 111:1211-1233.

Darbin O, Wichmann T (2008) Effects of striatal GABA A-receptor blockade on striatal and cortical activity in monkeys. J Neurophysiol 99:12941305.

DeLong MR, Crutcher MD, Georgopoulos AP (1985) Primate globus pallidus and subthalamic nucleus: functional organization. J Neurophysiol 53:530-543.

Farries MA, Kita H, Wilson CJ (2010) Dynamic spike threshold and zero membrane slope conductance shape the response of subthalamic neurons to cortical input. J Neurosci 30:13180-13191.

Firmin L, Field P, Maier MA, Kraskov A, Kirkwood PA, Nakajima K, Lemon RN, Glickstein M (2014) Axon diameters and conduction velocities in the macaque pyramidal tract. J Neurophysiol 112:1229-1240.

Froux L, Le Bon-Jego M, Miguelez C, Normand E, Morin S, Fioramonti S, Barresi M, Frick A, Baufreton J, Taupignon A (2018) D5 dopamine receptors control glutamatergic AMPA transmission between the motor cortex and subthalamic nucleus. Sci Rep 8:8858.

Fujimoto K, Kita H (1993) Response characteristics of subthalamic neurons to the stimulation of the sensorimotor cortex in the rat. Brain Res 609:185-192.

Galvan A, Wichmann T (2008) Pathophysiology of parkinsonism. Clin Neurophysiol 119:1459-1474.

Galvan A, Charara A, Pare JF, Levey AI, Smith Y (2004) Differential subcellular and subsynaptic distribution of $\mathrm{GABA}(\mathrm{A})$ and $\mathrm{GABA}(\mathrm{B})$ receptors in the monkey subthalamic nucleus. Neuroscience 127:709-721.

Galvan A, Kuwajima M, Smith Y (2006) Glutamate and GABA receptors and transporters in the basal ganglia: what does their subsynaptic localization reveal about their function? Neuroscience 143:351-375.

Georgopoulos AP, DeLong MR, Crutcher MD (1983) Relations between parameters of step-tracking movements and single cell discharge in the globus pallidus and subthalamic nucleus of the behaving monkey. J Neurosci 3:1586-1598.

Gouty-Colomer LA, Michel FJ, Baude A, Lopez-Pauchet C, Dufour A, Cossart R, Hammond C (2018) Mouse subthalamic nucleus neurons with local axon collaterals. J Comp Neurol 526:275-284.

Grabli D, McCairn K, Hirsch EC, Agid Y, Féger J, François C, Tremblay L (2004) Behavioural disorders induced by external globus pallidus dysfunction in primates: I. Behavioural study. Brain 127:2039-2054.

Hallworth NE, Bevan MD (2005) Globus pallidus neurons dynamically regulate the activity pattern of subthalamic nucleus neurons through the frequency-dependent activation of postsynaptic $G_{A B A}$ and $G_{A B A}$ receptors. J Neurosci 25:6304-6315.

Hamada I, DeLong MR (1992) Excitotoxic acid lesions of the primate subthalamic nucleus result in transient dyskinesias of the contralateral limbs. J Neurophysiol 68:1850-1858.

Hanson TL, Fuller AM, Lebedev MA, Turner DA, Nicolelis MA (2012) Subcortical neuronal ensembles: an analysis of motor task association, tremor, oscillations, and synchrony in human patients. J Neurosci 32:8620-8632

Hassani OK, Mouroux M, Féger J (1996) Increased subthalamic neuronal activity after nigral dopaminergic lesion independent of disinhibition via the globus pallidus. Neuroscience 72:105-115.

Isoda M, Hikosaka O (2008) Role for subthalamic nucleus neurons in switching from automatic to controlled eye movement. J Neurosci 28:72097218.

Iwamuro H, Tachibana Y, Ugawa Y, Saito N, Nambu A (2017) Information processing from the motor cortices to the subthalamic nucleus and globus pallidus and their somatotopic organizations revealed electrophysiologically in monkeys. Eur J Neurosci 46:2684-2701.

Jaeger D, Kita H (2011) Functional connectivity and integrative properties of globus pallidus neurons. Neuroscience 198:44-53.

Karube F, Takahashi S, Kobayashi K, Fujiyama F (2019) Motor cortex can directly drive the globus pallidus neurons in a projection neuron type-dependent manner in the rat. Elife 8:e49511.

Kita H (1992) Responses of globus pallidus neurons to cortical stimulation: intracellular study in the rat. Brain Res 589:84-90.

Kita H, Nambu A, Kaneda K, Tachibana Y, Takada M (2004) Role of ionotropic glutamatergic and GABAergic inputs on the firing activity of neurons in the external pallidum in awake monkeys. J Neurophysiol 92:3069-3084

Kita H, Chiken S, Tachibana Y, Nambu A (2006) Origins of $\mathrm{GABA}_{\mathrm{A}}$ and $\mathrm{GABA}_{\mathrm{B}}$ receptor-mediated responses of globus pallidus induced after stimulation of the putamen in the monkey. J Neurosci 26:6554-6562.

Kita T, Kita H (2011) Cholinergic and non-cholinergic mesopontine tegmental neurons projecting to the subthalamic nucleus in the rat. Eur J Neurosci 33:433-443.

Kitai ST, Deniau JM (1981) Cortical inputs to the subthalamus: intracellular analysis. Brain Res 214:411-415.

Kuwajima M, Hall RA, Aiba A, Smith Y (2004) Subcellular and subsynaptic localization of group I metabotropic glutamate receptors in the monkey subthalamic nucleus. J Comp Neurol 474:589-602.

Lavoie B, Parent A (1994) Pedunculopontine nucleus in the squirrel monkey: projections to the basal ganglia as revealed by anterograde tract-tracing methods. J Comp Neurol 344:210-231.

Levy R, Dostrovsky JO, Lang AE, Sime E, Hutchison WD, Lozano AM (2001) Effects of apomorphine on subthalamic nucleus and globus 
pallidus internus neurons in patients with Parkinson's disease. J Neurophysiol 86:249-260.

Limousin P, Pollak P, Benazzouz A, Hoffmann D, Le Bas JF, Broussolle E, Perret JE, Benabid AL (1995) Effect of parkinsonian signs and symptoms of bilateral subthalamic nucleus stimulation. Lancet 345:91-95.

Martínez-Fernández R, Rodríguez-Rojas R, Del Álamo M, HernándezFernández F, Pineda-Pardo JA, Dileone M, Alonso-Frech F, Foffani G, Obeso I, Gasca-Salas C, de Luis-Pastor E, Vela L, Obeso JA (2018) Focused ultrasound subthalamotomy in patients with asymmetric Parkinson's disease: a pilot study. Lancet Neurol 17:54-63.

Matsumura M, Kojima J, Gardiner TW, Hikosaka O (1992) Visual and oculomotor functions of monkey subthalamic nucleus. J Neurophysiol 67:1615-1632.

Maurice N, Deniau JM, Glowinski J, Thierry AM (1998) Relationships between the prefrontal cortex and the basal ganglia in the rat: physiology of the corticosubthalamic circuits. J Neurosci 18:9539-9546.

Monakow KH, Akert K, Künzle H (1978) Projections of the precentral motor cortex and other cortical areas of the frontal lobe to the subthalamic nucleus in the monkey. Exp Brain Res 33:395-403.

Mouroux M, Hassani OK, Féger J (1995) Electrophysiological study of the excitatory parafascicular projection to the subthalamic nucleus and evidence for ipsi- and contralateral controls. Neuroscience 67:399-407.

Nakanishi H, Kita H, Kitai ST (1987) Electrical membrane properties of rat subthalamic neurons in an in vitro slice preparation. Brain Res 437:3544.

Nambu A, Takada M, Inase M, Tokuno H (1996) Dual somatotopical representations in the primate subthalamic nucleus: evidence for ordered but reversed body-map transformations from the primary motor cortex and the supplementary motor area. J Neurosci 16:2671-2683.

Nambu A, Tokuno H, Hamada I, Kita H, Imanishi M, Akazawa T, Ikeuchi Y, Hasegawa N (2000) Excitatory cortical inputs to pallidal neurons via the subthalamic nucleus in the monkey. J Neurophysiol 84:289-300.

Nambu A, Kaneda K, Tokuno H, Takada M (2002a) Organization of corticostriatal motor inputs in monkey putamen. J Neurophysiol 88:18301842.

Nambu A, Tokuno H, Takada M (2002b) Functional significance of the cortico-subthalamo-pallidal "hyperdirect" pathway. Neurosci Res 43:111117.

Pasquereau B, Turner RS (2017) A selective role for ventromedial subthalamic nucleus in inhibitory control. Elife 6:e31627.

Rafols JA, Fox CA (1976) The neurons in the primate subthalamic nucleus: a Golgi and electron microscopic study. J Comp Neurol 168:75-111.

Reiner A, Albin RL, Anderson KD, D'Amato CJ, Penney JB, Young AB (1988) Differential loss of striatal projection neurons in Huntington disease. Proc Natl Acad Sci U S A 85:5733-5737.

Rodriguez-Oroz MC, Rodriguez M, Guridi J, Mewes K, Chockkman V, Vitek J, DeLong MR, Obeso JA (2001) The subthalamic nucleus in Parkinson's disease: somatotopic organization and physiological characteristics. Brain 124:1777-1790.

Rouzaire-Dubois B, Scarnati E (1987) Pharmacological study of the corticalinduced excitation of subthalamic nucleus neurons in the rat: evidence for amino acids as putative neurotransmitters. Neuroscience 21:429440.

Ryan LJ, Clark KB (1991) The role of the subthalamic nucleus in the response of globus pallidus neurons to stimulation of the prelimbic and agranular frontal cortices in rats. Exp Brain Res 86:641-651.

Ryan LJ, Clark KB (1992) Alteration of neuronal responses in the subthalamic nucleus following globus pallidus and neostriatal lesions in rats. Brain Res Bull 29:319-327.

Sadikot AF, Parent A, François C (1992) Efferent connections of the centromedian and parafascicular thalamic nuclei in the squirrel monkey: a PHA-L study of subcortical projections. J Comp Neurol 315:137-159.

Sano H, Chiken S, Hikida T, Kobayashi K, Nambu A (2013) Signals through the striatopallidal indirect pathway stop movements by phasic excitation in the substantia nigra. J Neurosci 33:7583-7594.

Sato F, Parent M, Levesque M, Parent A (2000) Axonal branching pattern of neurons of the subthalamic nucleus in primates. J Comp Neurol 424:142-152.

Schmidt R, Berke JD (2017) A Pause-then-Cancel model of stopping: evidence from basal ganglia neurophysiology. Philos Trans R Soc Lond B Biol Sci 372:20160202.

Schmidt R, Leventhal DK, Mallet N, Chen FJ, Berke JD (2013) Canceling actions involves a race between basal ganglia pathways. Nat Neurosci 16:1118-U1194

Smith Y, Charara A, Paquet M, Kieval JZ, Paré JF, Hanson JE, Hubert GW, Kuwajima M, Levey AI (2001) Ionotropic and metabotropic GABA and glutamate receptors in primate basal ganglia. J Chem Neuroanat 22:1342.

Storey E, Beal MF (1993) Neurochemical substrates of rigidity and chorea in Huntington's disease. Brain 116:1201-1222.

Swanger SA, Vance KM, Pare JF, Sotty F, Fog K, Smith Y, Traynelis SF (2015) NMDA receptors containing the GluN2D subunit control neuronal function in the subthalamic nucleus. J Neurosci 35:15971-15983.

Tachibana Y, Kita H, Chiken S, Takada M, Nambu A (2008) Motor cortical control of internal pallidal activity through glutamatergic and GABAergic inputs in awake monkeys. Eur J Neurosci 27:238-253.

Wang XS, Ong WY, Lee HK, Huganir RL (2000) A light and electron microscopic study of glutamate receptors in the monkey subthalamic nucleus. J Neurocytol 29:743-754.

Whittier JR, Mettler FA (1949) Studies on the subthalamus of the rhesus monkey; hyperkinesia and other physiologic effects of subthalamic lesions; with special reference to the subthalamic nucleus of Luys. J Comp Neurol 90:319-372.

Wichmann T, Bergman H, DeLong MR (1994) The primate subthalamic nucleus. I. Functional properties in intact animals. J Neurophysiol 72:494506.

Wilson CJ, Bevan MD (2011) Intrinsic dynamics and synaptic inputs control the activity patterns of subthalamic nucleus neurons in health and in Parkinson's disease. Neuroscience 198:54-68.

Yoshida S, Nambu A, Jinnai K (1993) The distribution of the globus pallidus neurons with input from various cortical areas in the monkeys. Brain Res 611:170-174. 